\title{
Hearing-impaired children in the UK, I: Auditory performance, communication skills, educational achievements, quality of life, and cochlear implantation
}

\author{
Paula C. Stacey ${ }^{1,2}$, Heather M. Fortnum ${ }^{1,3}$, Garry R. Barton ${ }^{1,4}$, A. Quentin \\ Summerfield ${ }^{1,2}$
}

${ }^{1}$ MRC Institute of Hearing Research, University Park, Nottingham NG7 2RD, UK.

${ }^{2}$ Now at Department of Psychology, University of York, Heslington, York YO10 5DD, UK.

${ }^{3}$ Now at the Trent Research and Development Support Unit, Nottingham University Medical School, Queen's Medical Centre, Nottingham NG7 2UH, UK.

${ }^{4}$ Now at the Division of Primary Care, School of Community Health Sciences, University of Nottingham, Nottingham, NG7 2RD, UK.

\author{
Submitted: $28^{\text {th }}$ May 2004 \\ Revised: $21^{\text {st }}$ March 2005 \\ Revised: $17^{\text {th }}$ September 2005
}

Corresponding author:

Professor Quentin Summerfield

Department of Psychology

University of York

York YO10 5DD

UK.

Telephone: (+44) 1904432913

e-mail: aqs1@york.ac.uk 


\begin{abstract}
Objectives: The objectives of this study were to identify variables which are associated with differences in outcome among hearing-impaired children, and to control those variables while assessing the impact of cochlear implantation.
\end{abstract}

Study design: In a cross-sectional study, the parents and teachers of a representative sample of hearing-impaired children were invited to complete questionnaires about children's auditory performance, spoken communication skills, educational achievements, and quality of life. Multiple regression was used to measure the strength of association between these outcomes and variables related to the child (average hearing level, age at onset of hearing impairment, age, gender, number of additional disabilities), the family (parental occupational skill level, ethnicity, and parental hearing status), and cochlear implantation.

Results: Questionnaires were returned by the parents of 2858 children, 468 of whom had received a cochlear implant, and by the teachers of 2241 children, 383 of whom had received an implant. Across all domains, reported outcomes were better for children with fewer disabilities in addition to impaired hearing. Across most domains, reported outcomes were better for children who were older, female, with a more favourable average hearing level, with a higher parental occupational skill level, and with an onset of hearing-impairment after 3 years. When these variables were controlled, cochlear implantation was consistently associated with advantages in auditory performance and spoken communication skills, but less consistently associated with advantages in educational achievements and quality of life. Significant associations were found most commonly for children who were younger than 5 years when implanted, and had used implants for more than 4 years. These 
children, whose mean (pre-operative, un-aided) average hearing level was $118 \mathrm{~dB}$, performed at the same level as non-implanted children with average hearing levels in the range from $80 \mathrm{~dB}$ to $104 \mathrm{~dB}$, depending on the outcome measure.

Conclusion: When rigorous statistical control is exercised in comparing implanted and non-implanted children, paediatric cochlear implantation is associated with reported improvements both in spoken communication skills and in some aspects of educational achievements and quality of life, provided that children receive implants before 5 years of age.

(342 words)

Key words: Childhood hearing impairment; cochlear implantation; auditory performance; communication skills; educational achievements; quality of life; ordinal logistic regression. 


\section{INTRODUCTION}

Summerfield and Marshall (1999) argued that cochlear implants are provided to young children in the expectation that immediate benefits in the domain of auditory receptive capabilities will trigger a cascade of further benefits in spoken communication skills, educational achievements, social independence, and quality of life. The cascade is reproduced in Figure 1. The greater the range of domains over which implantation is effective, the stronger the justification for implanting children. In principle, the effectiveness of implantation could be tested at any of the points in the cascade. In practice, too few implanted children have reached adulthood to permit tests across the entire range with adequate statistical power. Accordingly, the present study tested the restricted hypothesis that implantation is associated with enhanced short- and medium-term outcomes that are expected to emerge within a few years of implantation. Outcomes in the following four domains were selected on grounds of feasibility and informativeness.

\section{[FIGURE 1]}

\section{Choice of outcome domains}

Auditory performance: Implantation has been reported to be strongly associated with improvements in auditory performance (e.g. Boothroyd \& Eran, 1994; Nikolopoulos, Archbold, \& O'Donoghue, 1999). We obtained estimates of the ability of children to detect and interpret environmental sounds, and to respond to simple speech sounds, as indices of auditory performance.

Spoken communication skills: Implantation has been reported to be associated with improvements in speech perception (e.g. Blamey et al., 2001; Meyer, Svirsky, Kirk, \& Miyamoto, 1998; Osberger et al. 1991; Staller, Beiter, Brimacombe, Mecklenburg, \& 
Arndt, 1991[a]; Tyler, Fryauf-Bertschy, Gantz, Kelsay, \& Woodworth, 1997[a]), and speech production (Tobey, Geers, Brenner, Altuna, \& Gabbert, 2003). We obtained estimates of the ability to use, to understand, and to be understood when using, spoken language as indices of spoken communication skills.

Educational achievements: In the 1970's, profoundly hearing-impaired schoolleavers lagged their hearing peers by up to 7 years in reading, and up to 4 years in mathematics (Conrad, 1979; Quigley \& Kretschmer, 1982). The gap has closed since that time, probably as a result of earlier identification of deafness (e.g. Dalzell et al., 2000) and more effective early intervention (Moeller, 2000). Evidence has now been reported (e.g. Spencer, Barker, \& Tomblin, 2003; Tomblin, Spencer, \& Gantz, 2000) that implantation is associated with a further closing of the gap. We obtained three types of estimate of educational achievement: informal assessments of attainments in reading, writing, number work, and other quantitative skills, plus an estimate of reading age; formal assessments of progress through the National Curriculum obtained from Standard Assessment Tests; and assessments of participation and engagement in the process of education.

Quality of life: Studies of changes in quality of life associated with paediatric cochlear implantation have been of two sorts. First, parents have reported the relationship between their own expectations and outcomes (e.g. Kelsay \& Tyler, 1996; Nikolopoulos, Lloyd, Archbold, \& O'Donoghue, 2001). These studies emphasise the importance to parents of the emergence of skills in listening and communicating. Second, measures of children's health status (health-related quality of life) have been obtained by proxy from parents (Cheng et al., 2000; Barton, Stacey, Fortnum \& Summerfield, submitted[c]). We obtained estimates of two aspects of 
quality of life: 'child-centred' quality of life, estimated by parents and teachers in terms of a child's happiness, capacity to form friendships, and independence of function; and 'family-centred'quality of life, estimated by parents in relation to their own level of anxiety about their child, and about the degree of disruption to family life that they attributed to their child's hearing impairment.

\section{Choice of explanatory variables}

The study had a cross-sectional design in which outcomes in the four domains identified above were obtained for a representative sample of hearing impaired children, including children with implants and children without implants. A set of explanatory variables was also obtained for each child. Statistical analyses determined whether there was a significant association between implantation and each outcome measure, while controlling the influence of the other explanatory variables. The choice of explanatory variables was guided by three considerations. First, classes of variable were identified that have been shown to be independent predictors of outcomes within the general population of children, the hearing-impaired population, or the implanted population. Second, variables were identified that differ between the implanted and non-implanted populations of children in the UK (Fortnum, Marshall, \& Summerfield, 2002[b]). Third, additional variables were identified that were shown to differ between the implanted and non-implanted participants in the present study (Stacey, Fortnum, \& Summerfield, submitted). Nine explanatory variables were identified: average (pre-operative, unaided) hearing level, age at the onset of hearingimpairment, age, gender, number of additional disabilities, socio-economic status, ethnicity, parental hearing status, and mode of communication used in teaching.

Average hearing level: Amongst children without implants, many outcomes are 
poorer the greater the severity of the hearing loss (Bamford, Wilson, Atkinson, \& Bench, 1981; Blamey et al., 2001; Conrad, 1979; Svirsky, Sloan, Caldwell, \& Miyamoto, 2000[b]). Among hearing-impaired children in the UK, the average (preoperative, un-aided) hearing level (AHL) is significantly greater for children with implants than for hearing-impaired children without implants (Fortnum et al., 2002[b]). Thus, failure to control AHL when comparing implanted and non-implanted children might lead to an under-estimate of the effectiveness of implantation. AHL was claculated as the average of hearing levels at $0.5 \mathrm{Khz}, 1 \mathrm{kHz}, 2 \mathrm{kHz}$, and $4 \mathrm{kHz}$ (Footnote 1).

Age at onset of hearing-impairment: An older age at the onset of hearing impairment is associated with better outcomes in speech perception amongst nonimplanted children (Blamey et al., 2001) and implanted children (Blamey et al., 2001; Osberger et al., 1991; Staller et al., 1991[a]), and also with better outcomes in speech production and language among implanted and non-implanted children (Blamey et al., 2001). Among hearing-impaired children in the UK, the average age at the onset of hearing impairment is greater for children with implants than for children without implants (Fortnum et al., 2002[b]). Therefore, failure to control age at the onset of hearing impairment when comparing implanted and non-implanted children might lead to an over-estimate of the effectiveness of implantation.

Age: Communication skills improve with increasing age in the general population (Fenson et al., 2000; Mogford \& Bishop, 1993), the hearing-impaired population (Blamey et al., 2001; Meyer et al., 1998), and the implanted population (Blamey et al., 2001; Svirsky, Robbins, Kirk, Pisoni, \& Miyamoto, 2000[a]). The sample of children in the present study was drawn from the population of hearing-impaired 
children in the UK in 1998. At that time, children with implants were younger than the average of the population (Fortnum et al., 2002[b]). Thus, failure to control age when comparing implanted and non-implanted children might lead to an underestimate of the effectiveness of implantation.

Gender: In the UK and internationally, there are more hearing-impaired boys than girls, with an overall ratio of about 1.16 boys for every girl (Fortnum, 2003). However, in the UK, more girls than boys have cochlear implants (Fortnum et al., 2002[b]). In the general population, girls display better early communication skills (Fenson et al., 2000) and higher educational achievements than boys (Gillborn \& Mirza, 2000). A similar pattern has been documented in the hearing-impaired population (Allen, 1986; Easterbrooks \& O'Rourke, 2001) and in the implanted population (Geers, 2003; Tobey et al., 2003). Therefore, failure to control for gender when comparing implanted and non-implanted children might lead to an overestimate of the effectiveness of implantation.

Number of additional disabilities: Children with cochlear implants in the UK have fewer additional disabilities than other hearing-impaired children (Fortnum et al., 2002[b]). The US Department of Education Office of Special Education and Rehabilitative Services (2002) reported that pupils with disabilities dropped out of school at twice the rate of their peers, and that their enrolment in higher education was $50 \%$ lower than in the general population. Within the hearing-impaired population, negative effects of disabilities additional to hearing impairment have also been reported. For example, compared with hearing-impaired children with no additional disabilities, hearing-impaired children with additional disabilities display lower nonverbal IQ (Conrad, 1979) and achieve poorer educational qualifications as measured 
by national examinations at school leaving age (Powers, 2003). Although children with additional disabilities display improvements in the ability to perceive speech after cochlear implantation, the improvements emerge at a slower rate compared with children who have no additional disabilities (Holt \& Kirk, 2005; Pyman, Blamey, Lacy, Clark, \& Dowell, 2000; Rajput, Brown, \& Bamiou, 2003; Waltzman, Scalchunes, \& Cohen, 2000). Therefore, failure to control for other disabilities when comparing implanted and non-implanted children might lead to an over-estimate of the effectiveness of implantation.

Socio-economic status: Children with cochlear implants in the UK tend to come from more affluent families than children without implants (Fortnum et al., 2002[b]). Children from more affluent families tend to attain better communication skills and better educational attainments. These effects are found for children in the general population (Arriaga, Fenson, Cronan, \& Pethick, 1998; Gillborn \& Mirza, 2000), the hearing-impaired population (Kluwin, 1994; Powers, 2003; Van Den Horst, \& Kamstra, 1979), and the implanted population (Geers, 2003; Tobey et al., 2003). Therefore, failure to control for socio-economic status when comparing implanted with non-implanted children could lead to an over-estimate of the effectiveness of implantation.

Ethnicity: Compared with the white majority in the UK, members of ethnic minorities are more likely to be unemployed, to have lower levels of household income, and to live in low-income households (White, 2002). Additionally, the prevalence profile of disease and illness differs between ethnic minorities and the white majority (Donaldson \& Clayton, 1984), including the prevalence of childhood hearing impairment (Fortnum et al., 2002[b]). Children from some ethnic minorities 
attain lower educational qualifications (Gillborn \& Mirza, 2000; Powers, 2003), and hearing-impaired children from some ethnic minorities demonstrate lower levels of achievement than their white peers (Allen, 1986; Cohen, Fischgrund, \& Redding, 1990; Kluwin, 1994). The relationships among ethnicity, socio-economic status, and outcomes in health and education are complex and not fully understood. Accordingly, epidemiologists are encouraged to report the ethnic affiliations of study samples and to control ethnicity alongside socio-economic status.

Parental hearing status: Parental hearing status was included in the list of explanatory variables because some studies have concluded that hearing-impaired children born to hearing-impaired parents achieve better educational outcomes than hearing-impaired children who are born to hearing parents (Powers, 2003).

Communication mode: Children with cochlear implants in the UK are more likely than profoundly hearing-impaired non-implanted children to be taught using oral communication only (Fortnum, Marshall, Bamford, \& Summerfield, 2002[a]). Additionally, the percentage of implanted children who use oral communication increases with time after implantation (Archbold et al., 2000). Although it had been concluded that there is no difference in aural-oral skills between children using spoken language alone and children using a mixture of speaking and signing (Wilbur, 1979), more recent evidence suggests that speech perception, speech production, and oral communication skills are better amongst children who rely solely on an oral approach (e.g. Geers \& Moog, 1992). Advantages associated with oral communication have also been documented among children with implants (Archbold et al., 2000; Geers et al., 2000), where the amount of time spent speaking and listening is positively associated with better speech perception (Geers, Brenner, \& 
Davidson, 2003[a]), speech production (Tobey et al., 2003), and use of language (Geers, Nicholas, \& Sedey, 2003[b]). Although children may have performed better because they used oral approaches, it is also possible that children used oral-only approaches because they performed better, or were judged to have the capacity to perform better. The causal relationship between communication mode and outcomes is unclear (Dowell, Blamey, \& Clark, 1995). Nonetheless, in some analyses, we controlled the mode of communication in order to determine whether it explained an independent component of the variance in outcomes.

Previous studies of the effectiveness of paediatric cochlear implantation have adopted one of five experimental designs, as reviewed by Meyer et al. (1998) and by Summerfield (2002): prospective uncontrolled (e.g. Staller, Dowell, Beiter, \& Brimacombe, 1991[b]; Tyler, Fryauf-Bertschy et al., 1997[b]); historically controlled (e.g. Svirsky et al., 2000[a]; Tait \& Lutman, 1997); cross-sectional with crosssectional controls (e.g. Boothroyd \& Eran, 1994; Nakisa et al., 2001); prospective with cross-sectional controls (e.g. Meyer et al., 1998; Osberger et al., 1991; Snik, Vermeulen, Brokx, Beijk, \& van den Broek, 1997; Svirsky \& Meyer, 1999); and prospective with prospective controls (e.g. Blamey et al., 2001; Geers \& Moog, 1994). With the exception of the prospective case-control study by Geers and Moog (1994), none of these studies exercised control over as wide a range of variables as were included in this study, although a similar degree of control was exercised in explorations of the variables associated with different levels of outcome among implanted children (Geers \& Brenner, 2003).

\section{Main hypotheses}

The study tested two hypotheses: (1) Implantation is effective both in the 
short-term domains of auditory receptive capabilities and spoken communication skills, and in the medium-term domains of educational achievements and quality of life. (2) However, benefits of implantation are more robust, and emerge sooner after implantation, in short-term compared with medium-term domains. To address these hypotheses, we compared measures of the effectiveness of implantation between domains and, within domains, between groups of children who had used implants for different lengths of time. We made these comparisons with three measures of effectiveness: estimates of the strength of association between implantation and outcomes, estimates of the importance of implantation as an explanatory variable for outcomes compared with other variables, and estimates of functionally-equivalent, equivalent, and significant hearing levels.

\section{Functionally-equivalent, equivalent and significant hearing levels}

Several authors have summarised the results of comparisons between implanted and non-implanted children as a functionally-equivalent hearing level (Osberger et al., 1991; Osberger, Maso, \& Sam, 1993; Boothroyd \& Eran, 1994; Geers \& Moog, 1994; Snik et al., 1997; Meyer et al., 1998; Svirsky \& Meyer, 1999; Nakisa et al., 2001; Blamey et al., 2001). This is the unaided AHL of non-implanted children who achieve the same level of outcome as a child with an implant. Boothroyd and Eran (1994) argued that a functionally-equivalent hearing level can be more informative than the outcome score itself; that is, it can be more informative to learn that an implanted child whose unaided pre-operative AHL was, for example, $115 \mathrm{~dB}$ now functions like non-implanted children with an AHL of $85 \mathrm{~dB}$, than to be told that the implanted child achieves a score of $45 \%$ correct. A further advantage is that AHL is a common metric in which the effectiveness of implantation can be compared between domains. 
We estimated functionally-equivalent hearing levels along with two other values: the equivalent hearing level is the AHL at which the outcome score for implanted children is the same as the outcome score for non-implanted children; the significant hearing level is the lowest (most favourable) AHL at which the level of outcome for implanted children differs significantly from the level of outcome for non-implanted children. We used the methods described in the Appendix for estimating functionally-equivalent, equivalent, and significant hearing levels while controlling the effects of potentially confounding variables.

\section{Subsidiary questions}

\section{Mode of communication used in teaching}

Geers (2003; Geers et al., 2003[b]) identified explanatory variables for outcomes in the domains of language and reading in implanted children. Better outcomes were associated with variables in the child (e.g. higher IQ, female gender), the child's family (e.g. fewer siblings, high socio-economic status), and the implant system (e.g. modern processor, larger dynamic range). After accounting for variance in outcomes with these variables, the mode of communication used in teaching was significantly associated with the residual variance in each domain, such that better outcomes were associated with oral education. We first determined whether this result can be generalised by asking whether variables in the child and the child's family are associated with differences in outcome among hearing-impaired children generally, not just implanted children. We then examined whether residual differences in academic achievements can be explained by the mode of communication used in teaching. 


\section{$\underline{\text { Consequences of controlling different numbers of explanatory variables }}$}

In observational studies (i.e. studies like the present one where subjects are assigned to treatments by methods other than randomisation), variables that differ between cases and controls must be controlled if an accurate estimate of the effect of the treatment is to be obtained. In practice, it may not be practical to measure more than a few potentially confounding variables, and it is never possible to identify and measure all potentially confounding variables. Many previous comparisons of implanted and non-implanted children have controlled AHL and age only. To establish whether this is sufficient control, we compared the consequences of controlling those two variables alone and, separately, those two variables in combination with up to six other variables.

\section{Setting of the study}

The study involved hearing-impaired children from throughout the United Kingdom (UK) and included children who had received implants in every paediatric implant programme in the UK National Health Service. The overarching question, therefore, was whether paediatric cochlear implantation is a beneficial intervention when implants are delivered through a publicly-funded system of health care. That question concerns the effectiveness of implantation - does the intervention work when it is provided routinely? Effectiveness contrasts with efficacy - can the intervention work when it is provided under particular, maybe ideal, circumstances (Raftery, Stevens, \& Roderick, 2001)? As the provision of an intervention in health care matures, issues of effectiveness come to dominate issues of efficacy. Despite many demonstrations of the efficacy of implantation, and despite implantation having been routine in many countries for more than a decade, questions about effectiveness 
continue to be asked by parents, educators, clinicians, and commentators, as well as by the policy makers who commission health care. The questions arise because of the high initial and ongoing cost of implantation to systems of health care (Barton, Bloor, Marshall, \& Summerfield, 2003) and because of controversies associated with providing an elective surgical intervention to a deaf child (e.g. Balkany, Hodges, \& Goodman, 1998; Lane \& Bahan, 1999; Rubinstein, 2002).

\section{METHODS}

\section{Participants}

Previously, in 1998, we had ascertained the population of children in the UK with permanent bilateral hearing loss worse than $40 \mathrm{~dB}$ in the better-hearing ear (Fortnum, Summerfield, Marshall, Davis, \& Bamford, 2001). We identified 17,160 children. In 1999, the parents of a sample of 8876 of the children were invited to participate in the present study. The sample consisted of every child with a cochlear implant $(\mathrm{N}=993)$, every non-implanted child with a profound $(\mathrm{N}=3288)$ or severe $(\mathrm{N}=3580)$ hearing impairment, and approximately 1 in 9 of the children with moderate hearing impairments $(\mathrm{N}=1015)$.

\section{Procedure}

When parents consented, questionnaires were sent to the parents, teachers, and audiologists of the sampled children. Questions on communication skills, educational achievements, and quality of life were included in the parents' and teachers' questionnaires. Other questions, and questions in the audiologists' questionnaire, sought values of explanatory variables or asked about outcomes in other domains that are reported elsewhere (Barton, Stacey, Fortnum, \& Summerfield, submitted[a, c] 
Barton, Fortnum, Stacey, \& Summerfield, submitted [b]).

\section{Questions}

In this section, we summarise the questions that were put to parents and teachers. A supplementary document (Stacey, Fortnum, Barton, \& Summerfield, Reference Note 1) contains the wording of all questions. The questionnaires themselves can be obtained from MRC Institute of Hearing Research (Reference Note 2).

\section{$\underline{\text { Revised categories of auditory performance }}$}

Parents and teachers completed a revised version of the Categories of Auditory Performance (CAP). The CAP, as described by Archbold, Lutman, \& Marshall (1995), formed a category-referenced scale; i.e. an ordered series of statements describing performance of increasing complexity. The eight categories ranged from 'Is not aware of environmental sound' to 'Can use the telephone with a known speaker'. The ordering of the categories was validated by Archbold et al. (1995) and Nikolopoulos et al. (1999) who demonstrated that no category is attained by a child before all of the less complex categories have been attained. Following pilot testing, we modified the CAP for two reasons: first, to make it easier for parents and teachers to relate the questions to their everyday observations of children; second, to avoid a ceiling effect noted by Nikolopoulos et al. (1999) wherein $70 \%$ of implanted children attain one of the top two levels after 4 years of use of implants. The revised instrument is referred to as the $\mathrm{CAP}_{\mathrm{R}}$. It defines nine categories: (1) Is unaware of environmental sounds. (2) Is aware of environmental sounds. (3) Can identify some environmental sounds. (4) Can understand a few simple spoken words. (5) Can understand some common phrases. (6) Can understand a spoken conversation 
with a familiar person. (7) Can understand a spoken conversation with an unfamiliar person. (8) Can use the telephone with a familiar person. (9) Can use the telephone with an unfamiliar person. The highest level of the $\mathrm{CAP}_{\mathrm{R}}$ reported for each child was identified in each questionnaire that was returned. These levels were mapped onto two new variables, described in the next two sections, to estimate skills in Auditory Performance and, separately, skills in Speech Perception.

\section{Auditory performance}

To assess auditory performance, each child was mapped onto one of four levels of a new variable. Children at the first three levels of the $\mathrm{CAP}_{\mathrm{R}}$ were placed at the corresponding level of the new variable. Children at the fourth and higher levels of the $\mathrm{CAP}_{\mathrm{R}}$ were placed at the fourth level of the new variable.

\section{Spoken communication skills}

Parents and teachers were asked whether the child used spoken language. An estimate of how well the child could understand other people (Speech perception) was obtained by re-mapping levels of the $\mathrm{CAP}_{\mathrm{R}}$ onto a second new variable. Children at the first four levels of the $\mathrm{CAP}_{\mathrm{R}}$ were placed at the first level of the new variable. Children at the fifth and sixth levels were placed at the second and third levels of the new variable, respectively. Children at the seventh and higher levels of the $\mathrm{CAP}_{R}$ were placed at the fourth level of the new variable. An estimate of how well other people could understand the child (Speech intelligibility) was obtained from a further category-referenced scale, the Speech Intelligibility Rating (O'Donoghue, Nikolopoulos, Archbold, \& Tait, 1999), with four levels ranging from "No one can understand him" to "Most people can understand him" (Footnote 2). 


\section{Educational achievements}

Academic abilities: Parents and teachers judged children's abilities in reading, writing, number, time, money, and measurement using category-referenced scales. These scales were devised in consultation with teachers and parents, and with reference to the targets of the National Curriculum in England and Wales.

Key stages of the National Curriculum: The National Curriculum in England, Wales, and Northern Ireland is organised in four Key Stages (KS), at ages 5 to 7 years (KS 1), 7 to 11 years (KS 2), 11 to 14 years (KS 3), and 14 to 16 years (KS4, GCSE). At the end of Key Stages 1 to 3, pupils are assessed and achievement is scored at levels 1 to 8 on a single scale that is used throughout the three Key Stages. Teachers were asked which Key-stage level the child had attained in each of reading, writing, maths, and science.

Reading age: Teachers reported their best estimate of the child's reading age.

Participation and engagement in education: Teachers reported the ability of children to pay attention in small classes, how much instruction they believed children understood, and how engaged children were in group discussions. Responses were made on Likert scales. These questions were suggested by Chute (Reference Note 3).

\section{Quality of life}

Child and family: Parents reported how content they felt their child was, and how much their child's deafness affected family life.

Help (shop and friends): Parents reported how much help their child needed to buy something in a shop and to invite a friend to the house. 
Help (telephone and travel): Parents reported how much help their child required to use a telephone or public transport when away from home.

Socialisation: Teachers reported how easily the child made friends with deaf children and with hearing children at school, and how happy the child was at school.

All responses were made using Likert scales. Some questions in the Child and Family section were taken from a draft of the Child Health Questionnaire (Landgraf, Abetz, \& Ware, 1996) with the permission of the originator. Other questions were devised in consultation with teachers and parents.

\section{Derivation of summary outcome measures}

In order to restrict the number of analyses, while maintaining informativeness, sub-sets of the outcome measures in the educational-achievements and quality-of-life domains were summarised using categorical principal components analysis (Meulman \& Heiser, 1999). Analyses were performed on responses to questions in seven sections of the questionnaires: Academic abilities, Key-stage attainments, Participation and engagement, Child-and-family quality of life, Socialisation, Help (shop and friends), and Help (phone and travel). Each analysis yielded one or more principal components with a mean of zero and a standard deviation of unity.

\section{Encoding explanatory variables}

Explanatory variables were derived from data reported by parents, teachers, and audiologists in the ways described by Stacey et al. (submitted). Two were continuous variables (covariates): age and average (unaided, pre-operative) hearing level (AHL). The other eight were categorical variables (factors). The variables are defined in Table 1. The choice of whether to retain a continuous variable as a 
covariate or to make it a factor was informed by the distribution of scores. Continuous variables with skewed distributions were recast as factors. The number of levels of each factor, and the values of the levels, were chosen on the basis of exploratory analyses to be informative, and to achieve a balance between the level of detail in analyses, which was greatest when factors had many levels, and statistical power, which was greatest when each level of a factor included a large number of children.

\section{[TABLE 1]}

\section{Regression analyses}

Continuous outcome measures, including principal components, were analysed with multiple linear regression (Schroeder, Sjoquist, \& Stephan, 1986; Strube, 2003). Categorical outcome measures were analysed with ordinal logistic regression (Hosmer \& Lemeshow, 2000). Both types of analysis estimate the effect of each explanatory variable while controlling the effects of all other explanatory variables. Both allow explanatory variables to be either continuous (covariates) or categorical (factors). Both require covariates to vary linearly with the dependent variable. To meet the third requirement, we transformed age and AHL prior to each analysis using the methods described in the Appendix.

A key difference between the two forms of analysis is that, whereas the results of a linear regression are summarised by the weights (parameters) applied to variables in the linear equation, the results of an ordinal regression are summarised by odds ratios. A weight of zero or an odds ratio of one means that there is no association between the explanatory variable and the dependent variable. A weight greater than zero or an odds ratio greater than one means that higher levels of the dependent variable were attained, on average, by subjects who possessed the attribute than by 
subjects who did not possess the attribute.

Analyses were conducted in pairs. In the first analysis (Main Effects), the regression equations included only the main effects of the explanatory variables. These analyses were conducted to estimate the overall pattern of association of explanatory variables and to compare the relative importance of the explanatory variables. The second analysis (Interaction Effects) explored all plausible interactions between explanatory variables, and included those that explained significant amounts of variance in regression equations. We anticipated an interaction between cochlear implantation and AHL because spoken communication skills often decline with increasing AHL in children without implants (Bamford et al., 1981; Geers, 1997), but may be less dependent on AHL in children with implants (Tyler et al., 1997[a]). Therefore the effectiveness of implantation is likely to be larger for children with greater degrees of hearing loss than for children with lesser degrees of loss. We used the results of Interaction Effects analyses to calculate equivalent, functionally equivalent, and significant hearing levels using the methods described in the Appendix.

\section{Missing data}

To aid interpretation of other results, binary logistic regression analyses (Pampel, 2000) were performed to establish whether missing data arose at random or as a consequence of biases on the part of the respondents. Bias would be shown if data were more likely to be missing for children who possessed one value of a variable than another. 


\section{Analysis tools}

Categorical principal components analyses were conducted with the PRINCALS procedure (Meulman \& Heiser, 1999) in SPSS v. 12.0 (SPSS Inc., Reference Note 4). Multiple linear regression analyses and ordinal logistic regression analyses were conducted with SAS v 8.1 (Freund \& Littell, 2000).

\section{RESULTS}

\section{Reporting strategy}

The main results are reported here. Additional data and analyses are reported in the supplementary document (Stacey et al., Reference Note 1; Footnote 3).

\section{Response rates}

Consent to participate was received from the parents of 3274 children $(37 \%$ of those invited to participate), 527 of whom had a cochlear implant. Questionnaires were returned by the parents of 2858 children $(87 \%$ of those who consented to complete a questionnaire), 468 of whom had a cochlear implant, and by the teachers of 2241 children $(71 \%$ of those whose parents consented to their child's teacher being approached), 383 of whom had a cochlear implant. The samples of children for whom data were reported by parents and teachers overlapped substantially, with some data reported by both sources for 1990 children. Demographic and clinical details of these samples are reported elsewhere (Stacey et al., submitted). With only minor exceptions, the children were representative of the population of hearing-impaired children in the UK. Questionnaires were completed during 2000/1 and so describe the UK population of hearing-impaired children at that time. Some data were missing. The numbers of children for whom parents and teachers provided data in each domain 
are listed in Table 2. Note that data were not reported for high percentages of children for the two formal outcomes (reading age and key-stage attainments).

[TABLE 2]

Children with implants were placed in six groups defined by the combination of two ages at implantation ( $<5$ years and $\geq 5$ years) and three durations of use of implants ( $<2$ years, $\geq 2$ to $<4$ years, and $\geq 4$ years). The numbers of children in each group for whom data were received from parents and from teachers are given in Table 3. Mean values of the explanatory variables for the children for whom data were reported by parents are listed in Table 4. Similar values (not reported) were shown for the partially overlapping group of children for whom data were reported by teachers.

[TABLES $3 \& 4]$

\section{Preliminary analyses}

\section{Derivation of summary outcome measures}

Six of the seven categorical principal components analyses yielded a single principal component which correlated strongly with each of the quantified variables (coefficients of correlation ranging from 0.65 to 0.96 ) and explained a high percentage of the variance (percentages ranging from $62 \%$ to $90 \%$ ). The remaining analysis, of outcomes in the domain of quality of life, yielded seven principal components. Labels were assigned to indicate the underlying concept reflected by each component: 'Disruption' (to family life resulting from a child's hearing impairment), 'Satisfaction' (children's satisfaction with their lives), 'Feelings' (the frequency of occasions in which children were in different emotional states), 'Future' (parents' concern for their child's future), 'Friends' (children's confidence, ability to 
form friendships, and willingness to go to school), 'Behaviour' (the extent of children's behavioural problems, conflicts and arguments at home, and parental concern about behaviour), and 'Well-being' (children's physical and emotional wellbeing).

\section{Missing data}

Data tended to be missing for children with greater degrees of hearing impairment, who were younger, who had disabilities in addition to impaired hearing, with parents at lower occupational skill levels, and for non-implanted children. The variables that were associated with data being missing were often also associated with poorer outcomes. The likely effect of missing data, therefore was to inflate the estimate of outcomes associated with a variable, but to attenuate differences between groups. As a result, the strengths of association between implantation and outcomes, reported below, are likely to be conservative.

\section{Main analyses}

\section{$\underline{\text { Associations between explanatory variables and outcomes }}$}

As an illustration of the complete pattern of association for one outcome measure, Figure 2 plots the results of the Main Effects analysis of children's reported skills in speech perception. Filled and open circles plot odds ratios calculated from the data of parents and teachers, respectively. All but four odds ratios are significantly greater than one. Higher levels of speech perception were associated with variables in the child (better hearing, older age, fewer additional disabilities, older age at onset of hearing impairment, and female gender) and in the child's family (higher parental occupational skill level, and white ethnicity). There is close correspondence between results from parents and teachers (Footnote 4). 


\section{[FIGURE 2]}

Eleven of the 12 odds ratios in Figure 2 for the six groups of children with implants are significantly greater than one. Thus, children with implants were significantly more likely to be placed at higher levels of the categories of speech perception than children who were similar with respect to the other explanatory variables but who did not have implants. Table 5 includes those odds ratios along with corresponding values from Main Effects analyses of the other outcome measures (Footnote 5). Two trends can be seen. First, the strength of association of implantation with outcomes declines as one descends the table. For example, implantation was more strongly associated with enhanced auditory performance than with enhanced speech perception or speech intelligibility; implantation was consistently associated with enhanced outcomes in the domains of auditory performance and communication skills, but inconsistently associated with enhanced outcomes in the domains of educational achievements and quality of life. Second, for children implanted before the age of 5 years, the strength of association of implantation with enhanced auditory performance and communication skills increased with duration of use of implants (Footnote 6).

\section{[TABLE 5]}

Only a small proportion of the possible associations in the domains of educational achievements and quality of life, shown in the lower half of Table 5, were significant. This pattern would arise if the outcome measures were unresponsive to changes in outcome, independently of whether implantation was effective in changing outcomes. We hypothesised that weak associations would arise if outcome measures were insensitive to AHL. The logic of the hypothesis is that the first effect of 
implantation is to improve hearing sensitivity. Therefore a significant association would not be expected between implantation and an outcome measure that was itself insensitive to hearing sensitivity. Accordingly, we identified the sub-set of mediumterm outcome measures that displayed significant associations with AHL, and then checked whether they displayed associations with implantation. Results for those outcome measures are underlined in Table 5. Each of the five estimates of educational achievements showed a significant negative association with AHL, but only three of 30 possible associations with implantation were positive and significant. Of the nine analyses of quality of life, three showed significant negative associations with AHL, but only one of the 18 possible associations between those outcomes and implantation was positive and significant. Thus, even when consideration is restricted to outcomes with the potential to be responsive to implantation, significant positive associations between implantation and educational achievements and quality of life are limited.

One significant negative association is found in Table 5. Children implanted before the age of 5 years who had used their implants for between 2 and 4 years were judged by parents to display significantly poorer academic abilities than controls. We note that the same group of children, paradoxically, was the only one to display a significantly higher reading age than controls.

\section{Functionally-equivalent, equivalent, and significant hearing levels}

As an illustration of the estimation of equivalent and significant hearing levels, Figure 3 plots results from the Interaction Effects analysis of skills in the perception of spoken language reported by parents. The figure shows the interaction between AHL and implantation for each group of implanted children. The interaction was 
significant for five of the groups, allowing equivalent hearing levels, labelled 'e', to be estimated. A significant hearing level, labelled 's', could be estimated for all six groups.

An interaction between AHL and implantation arose with a probability less than 0.1 for at least one of the six combinations of age at implantation and duration of use of implants for four other outcome measures: Auditory performance, Speech intelligibility, Academic abilities, and Help (shop and friend). Where the data permitted, functionally-equivalent, equivalent, and significant hearing levels were calculated and are listed in Table 6 along with the values from Figure 3. Where outcomes for implanted children were estimated to be very good in relation to similar non-implanted children (Footnote 7), functionally-equivalent hearing levels were estimated to be below $80 \mathrm{~dB}$. Such values are listed as ' $<80 \mathrm{~dB}$ ' in Table 6 and were treated as $80 \mathrm{~dB}$ when averages were calculated. Where outcomes for implanted children were estimated to be poorer than outcomes for similar non-implanted children, functionally-equivalent hearing levels could exceed $130 \mathrm{~dB}$. Such values are listed as ' $>130 \mathrm{~dB}$ ' in Table 6 and were treated as $130 \mathrm{~dB}$ when averages were calculated.

Equivalent hearing levels ranged from $65 \mathrm{~dB}$ to $112 \mathrm{~dB}$ and displayed an advantage of $21 \mathrm{~dB}$ relative to the mean AHLs of the groups of children. Functionally-equivalent hearing levels ranged from $80 \mathrm{~dB}$ to $130 \mathrm{~dB}$ and displayed an average advantage of $16 \mathrm{~dB}$. Significant hearing levels ranged from 95 to $122 \mathrm{~dB}$ and displayed an average advantage of $9 \mathrm{~dB}$. The size of the advantage increased with duration of use, more obviously for children implanted before the age of 5 years than at or after 5 years. 
[FIGURE $3 \&$ TABLE 6]

\section{$\underline{\text { Relative importance of explanatory variables }}$}

The vertical bars in the left-hand panel of Figure 4 plot the median rank importance of the explanatory variables in the eight Main Effects analyses of outcomes in the domains of auditory performance and spoken communication skills. Importance was measured as the level of statistical significance of each variable. The variables have been ordered from left to right in order of decreasing importance. Bars for the six groups of implanted children have been highlighted. The dashed line plots the percentage of times each variable was significant out of a possible total of eight. The right-hand panel of Figure 4 shows corresponding results for the 14 analyses of academic achievements and quality of life. Age, AHL, and having two or more additional disabilities rank highly in both sets of analyses. Each combination of age at implantation and duration of use appears further to the left in the analyses of shortterm outcomes in the left-hand panel than in the analyses of medium-term outcomes in the right-hand panel, indicating that cochlear implantation has more influence on short-term outcomes.

\section{[FIGURE 4]}

\section{$\underline{\text { Consequences of controlling different numbers of explanatory variables }}$}

We conducted some additional Main Effects analyses to evaluate the consequences of not controlling every explanatory variable. First, an analysis was conducted with one explanatory variable only. This variable was the 7-valued factor which distinguished the six groups of implanted children and the group of nonimplanted children. The analysis was then repeated eight more times, with a further 
explanatory variable added to each successive calculation. The order in which the explanatory variables were introduced was the same as the ranking of their importance in the left-hand panel of Figure 4. Figure 5 shows illustrative results from two such analyses, chosen because effects of implantation were highly significant in one, but only marginally significant in the other. Panel A plots odds ratios from an ordinal logistic regression analysis of all 9 levels of the $\mathrm{CAP}_{\mathrm{R}}$ using data from parents. Panel B plots parameter values from a multiple linear regression analysis of the academic-abilities principal component using data from teachers. Results are shown for the two groups of children who had used implants for more then four years. For both outcomes, the strength of the association with implantation is approximately stable once AHL, additional disabilities, and age were included in the analysis. The judgement of whether or not the association is significant is independent of the number of explanatory variables for the $\mathrm{CAP}_{\mathrm{R}}$ in Panel A, but depends critically on the number of explanatory variables for academic abilities in Panel B.

\section{[FIGURE 5]}

\section{Mode of communication used in teaching}

The upper part of Table 7, labelled 'Analysis 1', lists the significance levels of explanatory variables in the Main Effects multiple linear regression analyses of outcomes in the domain of educational achievements. Variables describing children (age, age at the onset of deafness, AHL, number of additional disabilities) and children's families (parental occupational skill level) explained significant proportions of the variance among children in each analysis. Other variables describing children (gender) and children's families (parental hearing status and ethnicity) explained additional variance in a sub-set of the analyses. 
Of the 1828 children who could be included in these analyses because the complete set of explanatory variables had been reported for them, 1049 were taught using spoken language only, 10 using BSL only, 426 using BSL and another mode, and 208 using SSE or SE and another mode. One hundred and thirty five children were declared to have sufficient difficulty with communication to mean that they did not use conventional modes. Of them, 60 used Makaton (Footnote 8) and 75 used other special modes. When the residual variance from Analysis 1 was analysed according to the mode of communication used in teaching, significant advantages were found for children taught using spoken language only in comparison with other modes, except BSL only, where the numbers of children were too small for reliable conclusions to be drawn. These results are documented in the lower half of Table 7 where numbers in brackets report the percentages of the children for whom the outcome measure was missing.

\section{DISCUSSION}

\section{Short- and medium-term outcomes}

The results are compatible with the hypothesis (Summerfield \& Marshall, 1999) that outcomes from paediatric cochlear implantation form a cascade in which short-term outcomes in the domains of auditory performance and spoken communication skills emerge sooner after implantation and more strongly than medium-term outcomes in the domains of educational achievements and quality of life. That pattern is shown in three ways: in the significance of the associations between implantation and outcomes (Table 5), in the values of functionallyequivalent, equivalent, and significant hearing levels (Table 6), and in the importance of implantation relative to other explanatory variables for outcomes (Figure 4). 


\section{Patterns of association between implantation and outcomes}

Beyond the domains of auditory performance and speech perception, few statistically significant advantages of implantation were found unless children had received implants before the age of five years, and had used implants for more than four years. When those conditions were met, advantages were seen in each domain: implantation was associated with significant enhancements in auditory performance (judged by parents and teachers), speech perception (parents and teachers), speech intelligibility (parents and teachers), academic abilities (teachers), participation and engagement in the process of education (teachers), social independence reflected in the amount of help required to perform activities outside the home (parents), and socialisation (teachers).

Other studies have demonstrated that greater benefits are associated with a younger age at implantation (e.g. Fryauf-Bertschy, Tyler, Kelsay, Gantz, \& Woodworth, 1997; Kirk et al., 2002; Nikolopoulos et al. 1999; Tyler, Teagle et al., 2000; Svirsky et al., 2000[a]). Also, the cost-effectiveness of paediatric implantation (Barton et al., submitted[c]) is more favourable the younger the age at implantation. Arguably, implantation should be offered at the youngest age that is compatible with an assured diagnosis of profound hearing impairment and with the absence of increased surgical or anaesthetic risk (Svirsky, Teoh, \& Neuburger, 2004; Holt, Svirsky, Neuberger, \& Miyamoto, in press).

It is surprising that data from parents did not display significant associations between implantation and academic abilities, given that data from teachers did display this association. A possible explanation arises from considerations of missing data. Responses to questions about academic abilities were significantly more likely to be 
missing from the parents of non-implanted, than implanted, children. Data from teachers did not show this bias. For the reasons explained in the methods, if data are missing selectively for children who under-perform, differences in outcome between groups are attenuated. A further explanation might be that the parents of children with cochlear implants had higher expectations for their children compared with the parents of children without cochlear implants. As such, the parents of children with cochlear implants may have been judging academic performance more harshly, and comparing their children against a more stringent standard, than were the parents of children without cochlear implants.

Although there were few significant positive associations between implantation and outcomes in the quality-of-life domain, there were no significant negative associations. There is no evidence that implantation has a detrimental effect on quality of life.

\section{Functionally-equivalent, equivalent, and significant hearing levels}

Functionally-equivalent, equivalent, and significant hearing levels differed between groups of children and between outcome measures. The most favourable results occurred for the group of children who were younger than five years when implanted and had used their implants for more than four years. Their equivalent hearing levels ranged from 68-82 $\mathrm{dB}$ (auditory performance) to 96-107 $\mathrm{dB}$ (academic abilities); their functionally-equivalent hearing levels ranged from $<80 \mathrm{~dB}$ (auditory performance) to $87-104 \mathrm{~dB}$ (academic abilities); and their significant hearing levels ranged from 94-96 $\mathrm{dB}$ (auditory performance) to $112 \mathrm{~dB}$ (academic abilities). As a group, these children displayed consistent advantages relative to their mean AHL of $118 \mathrm{~dB}$. 
It is hard, nonetheless, to reconcile these results with the conclusion that children with implants display literacy skills that are similar to those displayed by their normally-hearing peers (Spencer, Tomblin, \& Gantz, 1997; Spencer et al., 2003; Tomblin et al., 2000; Watson, 2002). The discrepancy could have arisen from differences between those studies and the present one in age at implantation, in duration of use, in outcome measures, in the representativeness of the subjects, and in the variables over which control was exercised in comparing cases with controls.

More subtle is the apparent discrepancy between the present results and the suggestion that criteria of candidacy should be relaxed to include children with severe hearing impairments (Gordon, Twichell, Papsin, \& Harrison, 2001). The extent of the discrepancy depends on the rule that is chosen for determining candidacy and on the domain in which the rule is applied. The rule might require that children should benefit significantly more from implantation than from other forms of management, and the rule might be applied in the domain of speech perception. In which case, the criterion would be set in the range from 95 to $97 \mathrm{~dB}$, given the results for children implanted before the age of 5 years in Figure 3 and Table 6 . These values could be too conservative, however, insofar as significant hearing levels depend on the sample size as well as the effectiveness of implantation. Arguably, a comparison between sufficiently large samples of implanted and non-implanted children could show significant advantages for children with hearing levels only marginally less advantageous than the equivalent hearing level. In which case, the criterion could be set as favourably as $65 \mathrm{~dB}$, and compatibility would be found with the suggestion of Gordon et al. (2001). 
Two further issues are relevant, however. First, criteria of candidacy for implantation are not tied solely to hearing sensitivity but also include the requirement of a lack of benefit from, or a lack of response to, acoustic hearing aids. For this reason, estimates of functionally-equivalent, equivalent, and significant hearing levels may be better regarded as useful metrics in which to illustrate the practical impact of implantation, than as definitions of rigid boundaries of candidacy. Second, the key issue at the boundary of candidacy for interventions in health care is not only whether the intervention produces significant benefits, but whether the benefits are large enough to justify the cost of the intervention (e.g. UK Cochlear Implant Study Group, 2004). This issue is addressed for the present sample of children by Barton et al. (submitted $[\mathrm{a}, \mathrm{b}, \mathrm{c}])$.

\section{Interactions between implantation and other variables}

The strength of the association of implantation with outcomes did not vary with the occupational skill level of children's parents, which was used as a measure of socio-economic status. As the children sampled in the present study were more affluent than children in the hearing-impaired population (Stacey et al., submitted), it was important to establish whether the effectiveness of implantation varied according to socio-economic status. If it did, it would have been necessary to exercise care in generalising the results to the population of hearing-impaired children. The contrary finding - that the effect of cochlear implantation was consistent across socioeconomic groups - indicates that the present results can be generalised.

\section{Consequences of not controlling all explanatory variables}

Compared with non-implanted children with profound hearing-impairments, children with implants had greater degrees of hearing loss, were younger, came from 
more affluent families, had an older age at onset of hearing-impairment, and had fewer additional disabilities (Stacey et al., submitted). Potentially, there is a need to control each of these variables when assessing the influence of implantation because each of them is significantly associated with outcomes. However, in the present sample, some differences between implanted and non-implanted children work to the advantage of implanted children (fewer additional disabilities and older age at the onset of hearing impairment), while others work to their disadvantage (greater degree of hearing loss and younger age). The idea that these influences balance each other out may explain why there was little change in the strength of association of implantation with outcomes, once AHL, additional disabilities, and age were controlled (Figure 4). This result implies that other studies are likely to have achieved un-biased estimates of the effectiveness of implantation, provided that age, additional disabilities, and average hearing level were controlled and that the children who were studied were a representative sample of implanted and non-implanted children. There is a risk of circularity in stating the requirement in this way, of course, because confirmation of representativeness requires that several potentially confounding variables are measured.

\section{Mode of communication used in teaching}

The choice of spoken language as the only mode of communication used in teaching was associated with better educational achievements than were achieved with most other modes. The choice of mode could be causally related to outcomes. Alternatively, the choice could itself be influenced by a child's performance. Spoken communication might be chosen when children display the behavioural precursors (Tait, Lutman, \& Robinson, 2000) of competence in spoken language. The conclusion that the mode determines outcomes would be justified only if it could be proved either 
that the allocation of children to modes was random or that every other variable that determines outcomes had been controlled.

Moog and Geers (2003; Geers and Brenner, 2003) emphasised that the allocation of a child to a mode in North America is a consequence of the intersection of where a child happens to live with the educational policy in that geographic area. The allocation, therefore, can generally be regarded as random (providing that parents do not change residences to obtain certain services) allowing the conclusion that the choice of mode is causally related to outcomes. Undoubtedly, the same considerations apply for some children in the UK. For others, however, the choice of mode respects the needs of the child, the potential for the child to benefit, and the aspirations of parents. Therefore, the allocation of children to modes is not entirely random. Although we, like Geers and Brenner (2003), measured many explanatory variables, we cannot prove that we measured every variable that might influence outcomes. Therefore, caution is warranted in concluding from our data that the choice of spoken language causes better educational outcomes. We acknowledge, however, that the positive association between the choice of spoken language and outcomes is strong, even after adjustment for the effects of other explanatory variables.

\section{Parental hearing status}

Two outcome measures, academic abilities reported by parents and key-stage attainments reported by teachers, were significantly better for children whose parents had at least some difficulties with their own hearing. Compatible results were reported by Powers (2003). Reasons for the advantage could include earlier intervention for children identified as at-risk, and more informed and empathetic 
acceptance and management of hearing loss by parents who are themselves hearing impaired.

\section{Strengths and weaknesses}

This study had four weaknesses. First, its design was cross-sectional rather than longitudinal. Therefore, inferences about the emergence of outcomes with time following implantation were made by comparing different groups of children who had been implanted at different times and who may, therefore, have been managed in different ways. Second, cases and controls were determined by clinical judgement and parental choice, rather than by randomisation. Although we controlled many variables that might confound the comparison of implanted and non-implanted children, we cannot be sure that we controlled every relevant variable. Third, data were obtained indirectly by proxy from parents and teachers, rather than directly through performance tests and questionnaires administered to children themselves. Although there was broad agreement between the judgements of parents and teachers, despite their different perspectives, there was also evidence of bias, particularly on the part of parents, to avoid reporting data when outcomes were poor. The data are compatible with results in areas other than hearing impairment where parents' judgements of children's abilities are more favourable than teachers' judgements (Hauerwas \& Stone, 2000; Voelker, Shore, Lee, \& Szuszkiewicz, 2000). Fourth, the groups of children who had used implants for 4 years or more included children with a wide range of durations of use extending up to 10 years. Subdividing these groups, with the aim of identifying the minimal duration of use within this range at which medium-term outcomes were enhanced significantly, lost statistical power and was uninformative (Footnote 6). 
To set against these weaknesses are three strengths. First, the design allowed data to be obtained for a large sample of children who were shown to be representative of the population of hearing-impaired children in the UK. The results can be generalised, therefore. Second, estimates of the effectiveness of implantation were obtained in several domains for the same children. Demonstrably, therefore, the inconsistency of significant positive associations between implantation and outcomes in the domains of educational achievements and quality of life was not a consequence of implantation being ineffective in enhancing auditory performance and spoken communication skills. Moreover, the estimates of the effectiveness of implantation in improving skills in spoken communication are compatible with results of performance tests showing that outcomes from implantation are better amongst children who were younger when implanted and then improve with time after implantation (e.g. FryaufBertschy et al., 1997; Kirk et al., 2002; Nikolopoulos et al., 1999; Tyler, Teagle et al., 2000; Svirsky et al., 2004). Third, the study included contemporaneous controls. For these reasons, the results provide an informative illustration of the pattern of benefits that were gained when implants were provided to children through a publicly-funded system of health care in the late 1990's. Overall, the study provides evidence of the effectiveness of implantation that complements evidence of efficacy obtained in narrower, but deeper, studies.

\section{CONCLUSIONS}

This study of short- and medium-term outcomes for a representative sample of hearing-impaired children in the UK permits six conclusions. (1) Variations among children in short-term outcomes in auditory performance and spoken communication skills, and in medium-term outcomes in educational achievements and quality of life, are independently associated with variables related to the child and the family. 
(2) When these variables are controlled, positive associations between cochlear implantation and short-term outcomes are found consistently, while positive associations between implantation and medium-term outcomes are mainly limited to children who received implants before the age of five years and who had used implants for more than four years. (3) Within that group, children with pre-operative unaided 4-frequency average hearing levels greater than 94 to $112 \mathrm{~dB}$, depending on the outcome measure, display significantly better outcomes than similar nonimplanted children. The average unaided hearing level of non-implanted children who achieve the same levels of outcome as this group ranges from 80 to $104 \mathrm{db}$, depending on the outcome measure. (4) In terms of effectiveness, these results add to the evidence that implantation is justified when children with profound hearing loss receive implants before the age of 5 years and the goal is to create or retain the potential for using spoken language. (5) After accounting for differences in educational achievements among children with variables relating to the child and the family, a significant additional component of the residual variability can be explained by the mode of communication used in teaching, with advantages for children taught using spoken language only. This result is compatible with, but does not prove, a causal relationship between mode and outcomes. (6) There is a need for further wellcontrolled studies of outcomes for implanted children in educational achievements and quality of life. 


\section{FOOTNOTES}

1. In the UK, it has been traditional to summarise hearing sensitivity as the average of the hearing levels measured at $500 \mathrm{~Hz}, 1 \mathrm{kHz}, 2 \mathrm{kHz}$, and $4 \mathrm{kHz}$. We refer to this $4-$ frequency average as AHL. In North America, hearing sensitivity is often summarised as a 3 -frequency pure-tone average (PTA) computed at $500 \mathrm{~Hz}, 1 \mathrm{kHz}$, and $2 \mathrm{kHz}$. Values of AHL are expected to be numerically greater than values of PTA, because AHL includes higher frequencies where sensitivity is likely to be poorer. We assessed the consequences of using one metric rather than the other by comparing the PTA with AHL for 2378 children for whom both values could be calculated. The linear regression equation is $P T A=-0.916+0.987(A H L)$, with an adjusted r-squared of 0.97. On average, therefore, in the present sample of children, an AHL of $95 \mathrm{~dB}$ corresponds to a PTA of $93 \mathrm{~dB}$.

2. We assessed everyday communication skills in three modes independently: British Sign Language (BSL), spoken language, and Sign Supported English or Signed English (SSE/SE: modes in which signing is used to support the syntax of spoken English). Compatible questions were asked about performance in each mode. Analyses of data describing the use, perception, and intelligibility of BSL and SSE/SE are reported in a supplementary document (Stacey et al., Reference Note 1).

3. The supplementary document includes the detailed results of the principal components analyses (correlations between principal components and quantified variables; percentages of variance explained), of the regression analyses (odds ratios from binary logistic regression and ordinal logistic regression analyses; parameters from linear regression analyses), and of the binary logistic regression analyses of missing data. 
4. The $\mathrm{CAP}_{\mathrm{R}}$ was completed by both a parent and a teacher for 1707 children. When all 9 levels of the $\mathrm{CAP}_{\mathrm{R}}$ were considered, Cohen's measure of concordance, Kappa (SPSS, Reference Note 4), was 0.25 (95 percent confidence interval 0.22 to 0.27 ) showing significant agreement between parents and teachers, but at a level that would be judged no better than "fair" in the descriptive taxonomy of Landis and Koch (1977). This lack of detailed agreement was one reason for reporting results separately for parents and teachers.

5. The sections of the parents' questionnaire that provided the estimate of 'Help (phone and travel)' were completed for too few children to allow a meaningful Main Effects analysis. Instead, parents reported that children did not do these activities. An analysis in which the 7-valued implantation factor was reduced to two values, (i) implanted and (ii) non-implanted, showed a significant positive effect of implantation with a parameter value of $0.502(\mathrm{p}<0.01)$.

6. Five outcomes in Table 5 for children implanted before the age of 5 years show significant enhancement for children who had used their implants for 4 years or more, but not for children who had used their implants for between 2 and 4 years. To seek evidence of the shortest duration of use for which these outcomes were significantly enhanced, additional analyses were performed. Children implanted before the age of 5 years who had used devices for 4 years or more were sub-divided into a group with 4 to 6 years of use and a group with 6 or more years of use. For academic abilities reported by teachers, the effect for the group with 4-6 years of use was +0.20 with a 95 percent confidence interval extending from -0.01 to +0.41 , and for the group with 6 or more years of use the effect was $+0.17(-0.02$ to +0.36$)$. Corresponding results for the other four outcomes were: participation and engagement (4-6 years) +0.27 
$(-0.05$ to +0.58$)$ and $(\geq 6$ years $)+0.19(-0.09$ to +0.47$)$; future concerns (4-6 years) $+0.22(-0.18$ to +0.63$)$ and $(\geq 6$ years $)+0.45(+0.10$ to +0.79$)$; help (shop and friend) $(4-6$ years $)+0.40(+0.08$ to +0.71$)$ and $(\geq 6$ years $)+0.13(-0.13$ to +0.38$)$; sociability $(4-6$ years $)+0.23(-0.11$ to +0.56$)$ and $(\geq 6$ years $)+0.29(-0.03$ to +0.60$)$. In general, therefore, the size of the effect for children with 4 to 6 years of use was the same as the size of effect for children with 6 years or more of use. However, the loss of statistical power that resulted from subdividing the groups meant that effects were rarely significant for the sub-divided groups.

7. This situation is described in Figure 6c and the Appendix.

8. Makaton is a signed communication mode used in the UK. It is based on whole word signs and pictures and is most often used with children with learning difficulties in addition to hearing impairment. 


\section{ACKNOWLEDGEMENTS}

This study was supported by the Medical Research Council, Defeating Deafness-The Hearing Research Trust, and the National Lottery Charities Board. We thank all children, parents, teachers, and health carers who provided data. Ms D Betts, Ms S Holroyd, and Ms M Shaw coded and checked data. Dr DH Marshall, Professor AC Davis, Professor JM Bamford, and Dr KE Bloor provided advice and guidance in formulating the design and methods of execution of the study. Dr DH Marshall programmed the databases that supported the study and guided initial analyses of the data. We thank Mrs Susan Archbold who commented critically on drafts of the questionnaires. 


\section{REFERENCES}

Allen, T. E. (1986). Patterns of academic achievement among hearing impaired students: 1974 and 1983. In Deaf Children in America (A. Schildroth, \& S. Karchmer, Eds.). College Hill Press, San Diego, USA.

Archbold, S., Lutman, M. E., \& Marshall, D. H. (1995). Categories of auditory performance. Annals of Otology, Rhinology and Laryngology, 104, 312-314.

Archbold, S., Nikolopoulos, T. P., Tait, M., O'Donoghue, G. M., Lutman, M. E., \& Gregory, S. (2000). Approach to communication, speech perception and intelligibility after paediatric cochlear implantation. British Journal of Audiology, 34, 257-264.

Arriaga, R. I., Fenson, L., Cronan, T., \& Pethick, S. J. (1998). Scores on the MacArthur communicative development inventory of children from low- and middle-income families. Applied Psycholinguistics, 19, 209-223.

Balkany, T., Hodges, A. V., \& Goodman, K. W. (1998). Cochlear Implants for Young Children: Ethical Issues. In Cochlear Implants for Kids (W. Estabrooks, Ed.). Alexander Graham Bell Association, Washington D.C.

Bamford, J. M., Wilson, I. M., Atkinson, D., \& Bench, J. (1981). Pure-tone audiograms from hearing impaired children: predicting speech-hearing from the audiogram. British Journal of Audiology, 15, 3-10.

Barton, G. R., Bloor, K. E., Marshall, D. H., \& Summerfield, A. Q. (2003). Healthservice costs of pediatric cochlear implantation: multi-center analysis. International Journal of Pediatric Otorhinolaryngology, 67, 141-149.

Barton, G.R., Stacey, P.C., Fortnum, H.M., \& Summerfield, A.Q. (submitted[a]). Hearing-impaired children in the UK, II: Cochlear implantation and the cost of compulsory education. Ear and Hearing. 
Barton, G.R., Fortnum, H.M., Stacey, P.C. \& Summerfield, A.Q. (submitted[b]). Hearing-impaired children in the UK, III: Cochlear implantation and the economic costs incurred by families.

Barton, G.R., Stacey, P.C., Fortnum, H.M. \& Summerfield, A.Q. (submitted[c]). Hearing-impaired children in the UK, IV: Cost-effectiveness of paediatric cochlear implantation.

Blamey, P. J. et al. (2001). Relationships among speech perception, production, language, hearing loss, and age in children with impaired hearing. Journal of Speech, Language and Hearing Research, 44, 264-285.

Boothroyd, A., \& Eran, O. (1994). Auditory speech perception capacity of child implant users expressed as equivalent hearing loss. Volta Review, 95, 151-167.

Cheng, A. K., Rubin, H. R., Powe, N. R., Mellon, N. K., Francis, H. W., \& Niparko, J. K. (2000). Cost-utility analysis of the cochlear implant in children. Journal of the American Medical Association, 284, 850-856.

Cohen, O. P., Fischgrund, J. E., \& Redding, R. (1990). Deaf children from ethnic, linguistic and racial minority backgrounds: An overview. American Annals of the Deaf, 135, 67-73.

Conrad, R. (1979). The Deaf School Child. Harper \& Row, London.

Dalzell, L. et al. (2000). The New York State universal newborn hearing screening demonstration project: ages of hearing loss identification, hearing aid fitting, and enrolment in early intervention. Ear and Hearing, 21, 118-130.

Donaldson, L. J., \& Clayton, D. G. (1984). Occurrence of cancer in Asians and nonAsians. Journal of Epidemiology and Community Health, 38, 203-207. 
Dowell, R. C., Blamey, P. J., \& Clark, G. M. (1995). Potential and limitations of cochlear implants in children. Annals of Otology, Rhinology and Laryngology Supplement, 166, 324-327.

Easterbrooks, S. R., \& O'Rourke, C. M. (2001). Gender differences in response to auditory-verbal intervention in children who are deaf or hard of hearing. American Annals of the Deaf, 146, 309-319.

Fenson, L., Pethnick, S., Renda, C., Cox, J. L., Dale, P. S., \& Reznick, J. S. (2000). Short-form versions of the MacArthur communicative development inventories. Applied Psycholinguistics, 21, 95-115.

Fortnum, H. (2003). Epidemiology of permanent childhood hearing impairment: implications for neonatal hearing screening. Audiological Medicine, 1, 155-164.

Fortnum, H. M., Marshall, D. H., Bamford, J. M., \& Summerfield, A. Q. (2002[a]). Hearing-impaired children in the UK: education setting and communication approach. Deafness and Education International, 4, 123-141.

Fortnum, H. M., Marshall, D. H., \& Summerfield, A. Q. (2002[b]). Epidemiology of the United Kingdom population of hearing-impaired children including characteristics of those with and without cochlear implants - audiology, etiology and affluence. International Journal of Audiology, 41, 170-179.

Fortnum, H. M., Summerfield, A. Q., Marshall, D. H., Davis, A. C., \& Bamford, J. M. (2001). Prevalence of permanent childhood hearing impairment in the United Kingdom and implications for universal neonatal screening: questionnaire based ascertainment study. British Medical Journal, 232, 1-6.

Freund, J. R., \& Littell, R. C. (2000). SAS System for Regression. BBU Press and John Wiley Sons Inc., Cary NC. 
Fryauf-Bertschy, H., Tyler, R. S., Kelsay, D. M., Gantz, B. J., \& Woodworth, G. G. (1997). Cochlear implant use by prelingually deafened children: The influences of age at implant and length of device use. Journal of Speech, Language and Hearing Research, 40, 183-199.

Geers, A. E. (1997). Speech and language evolution in aided and implanted children. Scandinavian Audiology Supplement, 46, 72-75.

Geers, A. E. (2003). Predictors of reading skill development in children with early cochlear implantation. Ear and Hearing, 24, 59S-68S.

Geers, A. E., \& Brenner, C. (2003). Background and educational characteristics of prelingually deaf children implanted by five years of age. Ear and Hearing, 24, $2 \mathrm{~S}-14 \mathrm{~S}$

Geers, A. E., Brenner, C., \& Davidson, L. (2003[a]). Factors associated with development of speech perception skills in children implanted by age five. Ear and Hearing, 24, 24S-35S

Geers, A. E., \& Moog, J. S. (1992). Speech perception and production skills of students with impaired hearing from oral and total communication settings. Journal of Speech, Language and Hearing Research, 35, 1384-1393.

Geers, A. E., \& Moog, J. S. (1994). Effectiveness of cochlear implants and tactile aids for deaf children: the Sensory Aids Study at the Central Institute for the Deaf. In, Volta Review. Washington: AG Bell Association for the Deaf.

Geers, A. E. et al. (2000). Effects of communication mode on skills of long-term cochlear implant users. Annals of Otology, Rhinology and Laryngology Supplement, 185, 89-92.

Geers, A. E., Nicholas, J. G., \& Sedey, A. L. (2003[b]). Language skills of children with early cochlear implantation. Ear and Hearing, 24, 46S-58S. 
Gillborn, D., \& Mirza, H. S. (2000). Educational inequality: mapping race, class and gender. Office for Standards in Education, London.

Gordon, K. A., Twichell, K. A., Papsin, B. C., \& Harrison, R. V. (2001). Effect of residual hearing prior to cochlear implantation on speech perception in children. Journal of Otolaryngology, 30, 216-223.

Hauerwas, L. B., \& Stone, C. A. (2000). Are parents of school-age children with specific language impairments accurate estimators of their child's language skills. Child Language Teaching and Therapy, 16, 73-86.

Holt, R. F., \& Kirk, K. I. (2005). Speech and language development in cognitively delayed children with cochlear implants. Ear and Hearing, 26, 132-148.

Holt, R. F., Svirsky, M. A., Neuburger, H., \& Miyamoto, R. T. (in press). Age at implantation and communicative outcome in pediatric cochlear implant users: Is younger always better? International Congress Series.

Hosmer, D. W., \& Lemeshow, S. (2000). Applied Logistic Regression. Wiley Interscience, New York.

Kelsay, D. M., \& Tyler, R. S. (1996). Advantages and disadvantages expected and realized by pediatric cochlear implant recipients as reported by their parents. American Journal of Otology, 17, 866-873.

Kirk, K. I., Miyamoto, R. T., Lento, C. L., Ying, E., O'Neill, T., \& Fears, B. (2002). effects of age at implantation in young children. Annals of Otology, Rhinology and Laryngology Supplement, 189, 69-73.

Kluwin, T. N. (1994). The interaction of race, gender and social class effects in the education of deaf students. American Annals of the Deaf, 139, 465-471.

Landgraf, J., Abetz, L., \& Ware, J. (1996). Child Health Questionnaire (CHQ): A User's Manual. Health Act, Boston, MA. 
Landis, J. R., \& Koch, G. G. (1977). The measurement of observer agreement for categorical data. Biometrics, 33, 159-174.

Lane, H., \& Bahan, B. (1999). Ethics of cochlear implantation in young children. Otolaryngology - Head and Neck Surgery, 121, 672-675.

Meulman, J. J., \& Heiser, W. J. (1999). SPSS Categories 10.0. SPSS Inc., Chicago.

Meyer, T. A., Svirsky, M. A., Kirk, K. I., \& Miyamoto, R. T. (1998). Improvements in speech perception by children with profound prelingual hearing loss: Effects of device, communication mode, and chronological age. Journal of Speech, Language and Hearing Research, 41, 846-858.

Moeller, M. P. (2000). Early intervention and language development in children who are deaf and hard of hearing. Pediatrics, 106, E43.

Mogford, K., \& Bishop, D. (1993). Language development in unexceptional circumstances. In Language development in exceptional circumstances (D. Bishop, \& K. Mogford, Eds.), pp. 10-28. Lawrence Erlbaum, Hove/Hillsdale.

Moog, J. S., \& Geers, A. E. (2003). Epilogue: major findings, conclusions and implications for deaf education. Annals of Otology, Rhinology and Laryngology, 24, 121S-125S.

Nakisa, M. J. et al. (2001). Functionally equivalent ages and hearing levels of children with cochlear implants with pre-recorded stimuli. British Journal of Audiology, 35, 183-199.

Nikolopoulos, T. P., Archbold, S. M., \& O'Donoghue, G. M. (1999). The development of auditory perception in children following cochlear implantation. International Journal of Pediatric Otorhinolaryngology, 49, 189-191. 
Nikolopoulos, T. P., Lloyd, H., Archbold, S., \& O'Donoghue, G. M. (2001). Pediatric cochear implantation: The parents' perspective. Archives of Otolaryngology, Head and Neck Surgery, 127, 363-367.

O'Donoghue, G. M., Nikolopoulos, T. P., Archbold, S., \& Tait, M. (1999). Cochlear implants in young children: The relationship between speech perception and speech intelligibility. Ear and Hearing, 20, 419-425.

Osberger, M. J., Maso, M., \& Sam, L. K. (1993). Speech intelligibility of children with cochlear implants, tactile aids, or hearing aids. Journal of Speech and Hearing Research, 36, 186-203.

Osberger, M. J. et al. (1991). Speech perception abilities of children with cochlear implants, tactile aids, or hearing aids. Journal of Speech and Hearing Research, 36, 186-203.

Pampel, F. C. (2000). Logistic Regression: A Primer. Sage, Thousand Oaks, CA.

Powers, S. (2003). Influences of student and family factors on academic outcomes of mainstream secondary school deaf students. Journal of Deaf Studies and Deaf Education, 8, 57-78.

Pyman, B., Blamey, P. J., Lacy, P., Clark, G. M., \& Dowell, R. C. (2000). The development of speech production in children using cochlear implants: Effects of etiologic factors and delayed milestones. American Journal of Otology, 21, $57-61$.

Quigley, S. P., \& Kretschmer, R. E. (1982). The Education of Deaf Children: Issues, Theory and Practice. Edward Arnold, London.

Raftery, J., Stevens, A., \& Roderick, P. (2001). The potential use of routine datasets in health technology assessment. In The Advanced Handbook of Methods in 
Evidence Based Healthcare (A. Stevens, K. Abrams, J. Brazier, R. Fitzpatrick, \& R. Lilford, Eds.), pp. 136-148. Sage, London.

Rajput, K., Brown, T., \& Bamiou, D. (2003). Aetiology of hearing loss and other related factors versus language outcome after cochlear implantation in children. International Journal of Pediatric Otorhinolaryngology, 67, 497-504.

Rubinstein, J. T. (2002). Paediatric cochlear implantation: prosthetic hearing and language development. The Lancet, 360, 483-485.

Schroeder, L. D., Sjoquist, D. L., \& Stephan, P. E. (1986). Understanding regression analysis: An introductory guide. Sage Publications, Thousand Oaks, CA.

Snik, A. F., Vermeulen, A. M., Brokx, J. P., Beijk, C., \& van den Broek, P. (1997). Speech perception performance of children with a cochlear implant compared to that of children with conventional hearing aids. I. The 'equivalent hearing loss' concept. Acta Oto-Laryngologica, 117, 750-754.

Spencer, L. J., Barker, B. A., \& Tomblin, B. (2003). Exploring the language and literacy outcomes of pediatric cochlear implant users. Ear and Hearing, 24, 236247.

Spencer, L., Tomblin, J. B., \& Gantz, B. J. (1997). Reading skills in children with multichannel cochlear-implant experience. Volta Review, 99, 193-202.

Stacey, P.C., Fortnum, H.M., \& Summerfield, A.Q. (submitted). Questionnaire survey of hearing-impaired children: an assessment of representativeness and a demographic comparison of children with and without cochlear implants. International Journal of Audiology.

Staller, S. J., Beiter, A. L., Brimacombe, J. A., Mecklenburg, D. J., \& Arndt, P. (1991[a]). Pediatric performance with the Nucleus 22-channel cochlear implant system. American Journal of Otology, 12, 126-136. 
Staller, S. J., Dowell, R. C., Beiter, A. L., \& Brimacombe, J. A. (1991[b]). Perceptual abilities of children with the Nucleus 22-channel cochlear implant. Ear and Hearing, 12, 34S-47S.

Strube, M. J. (2003). Statistical analysis and interpretation in a study of prelingually deaf children implanted before five years of age. Ear and Hearing, 24, 15S $23 \mathrm{~S}$.

Summerfield, A. Q. (2002). A critical appraisal of the evidence base for cochlear implantation. In Cochlear Implantation: Cost Creating or Cost Saving? Proceedings of a Conference on Health Technology Assessment. Hughes Associates, Oxford.

Summerfield, A. Q., \& Marshall, D. H. (1999). Paediatric cochlear implantation and health-technology assessment. International Journal of Pediatric Otorhinolaryngology, 47, 141-151.

Svirsky, M. A., \& Meyer, T. A. (1999). Comparison of speech perception for pediatric Clarion cochlear implant and hearing aid users. Annals of Otology, Rhinology and Laryngology, 108, 104-109.

Svirsky, M. A., Robbins, A. M., Kirk, K. I., Pisoni, D. B., \& Miyamoto, R. T. (2000[a]). Language development in profoundly deaf children with cochlear implants. Psychological Science, 11, 153-158.

Svirsky, M. A., Sloan, R. B., Caldwell, M., \& Miyamoto, R. T. (2000[b]). Speech intelligibility of prelingually deaf children with multichannel cochlear implants. Annals of Otology, Rhinology and Laryngology Supplement, 185, 123-125.

Svirsky, M. A., Teoh, S-W., \& Neuberger, H. (2004). Development of language and speech perception in congenitally, profoundly deaf children as a function of age at cochlear implantation. Audiology \& Neuro-Otology, 9,224-233. 
Tait, M., \& Lutman, M. E. (1997). The predictive value of measures of preverbal communicative behaviours in young deaf children with cochlear implants. Ear and Hearing, 18, 472-478.

Tait, M., Lutman, M. E., \& Robinson, K. (2000). Preimplant measures of preverbal communicative behaviour as predictors of cochlear implant outcomes in children. Ear and Hearing, 21, 18-24.

Tobey, E. A., Geers, A. E., Brenner, C., Altuna, D., \& Gabbert, G. (2003). Factors associated with development of speech production skills in children implanted by age five. Ear and Hearing, 24, 36S-45S.

Tomblin, J. B., Spencer, L., \& Gantz, B. J. (2000). Language and reading acquisition in children with and without cochlear implants. Advances in Oto-RhinoLaryngology, 57, 300-304.

Tyler, R. S., Fryauf-Bertschy, H., Gantz, B., Kelsay, D., \& Woodworth, G. (1997[a]). Speech perception in prelingually implanted children after four years. Advances in Otorhinolaryngology, 52, 187-192.

Tyler, R. S., Fryauf- Bertschy, H., Kelsay, D. M., Gantz, B. J., Woodworth, G. P., \& Parkinson, A. J. (1997[b]). Speech perception by prelingually deaf children using cochlear implants. Otolaryngology - Head and Neck Surgery, 117, 180187.

Tyler, R. S., Teagle, H. F. B., Kelsay, D. M., Gantz, B. J., Woodworth, G. G., \& Parkinson, A. J. (2000). Speech perception by prelingually deaf children after six years of cochlear implant use: Effects of age at implantation. Annals of Otology, Rhinology and Laryngology Supplement, 185, 82-84. 
UK Cochlear Implant Study Group (2004). Criteria of candidature for unilateral cochlear implantation in post-lingually deafened adults I: theory and measures of effectiveness. Ear and Hearing, 25, 310-335.

US Department of Education Office of Special Education and Rehabilitative Services (2002). A New Era: Revitalizing Special Education for Children and Their Families. Washington DC.

Van Den Horst, A. P. J. M., \& Kamstra, O. W. M. (1979). Social class, defective hearing, and language. Journal of Communication Disorders, 12, 217-228.

Voelker, S. L., Shore, D. L., Lee, C. H., \& Szuszkiewicz, T. A. (2000). Congruence in parent and teacher ratings of adaptive behavior of low-functioning children. Journal of Developmental and Physical Disabilities, 12, 367-376.

Waltzman, S. B., Scalchunes, V., \& Cohen, N. L. (2000). Performance of multiply handicapped children using cochlear implants. American Journal of Otology, 21, $329-335$.

Watson, L. (2002). The literacy development of children with cochlear implants at age seven. Deafness and Education International, 4, 84-98.

White, A. (2002). Social Focus in Brief: Ethnicity 2002. Office for National Statistics, London.

Wilbur, R. B. (1979). American Sign Language and Sign Systems. University Park Press, Baltimore. 


\section{REFERENCE NOTES}

1. Stacey, P.C., Fortnum, H.M., Barton, G.R., \& Summerfield A.Q. (2005). Hearingimpaired children in the UK, I: Auditory performance, communication skills, educational achievements, quality of life, and cochlear implantation (Supplementary Information). Accessed from www.ihr.mrc.ac.uk/publications/papers/nesodhic on 25th February, 2005.

2. MRC Institute of Hearing Research (2005). National Study of Support Options for Deaf and Hearing-impaired Children: Questionnaires. Accessed from www.ihr.mrc.ac.uk/publications/papers/nesodhic on $25^{\text {th }}$ February, 2005.

3. Chute, P. (1999). Personal Communication.

4. SPSS Inc. (2002). SPSS for Windows Release 11.0. Chicago, Illinois. 


\section{Appendix}

\section{$\underline{\text { Regression analyses }}$}

Multiple linear regression (Schroeder et al., 1986; Strube, 2003) and ordinal logistic regression (Hosmer \& Lemeshow, 2000) both account for variation among subjects in a dependent variable by a linear weighted combination of explanatory variables. However, whereas linear regression requires the dependent variable to be continuous, unbounded, and measured on an interval scale, ordinal regression allows the dependent variable to be categorical, bounded, and measured on an ordinal scale. In linear regression, the linear weighted combination of explanatory variables predicts values of the dependent variable directly by minimising the squared deviation of predicted from observed values. The results are summarised by the values of the weights applied to the explanatory variables in the regression equation. In ordinal regression, the linear weighted combination estimates values of the logit of the dependent variable using the technique of maximum likelihood. The results are summarised by an odds ratio for each explanatory variable.

An odds ratio is the ratio of two odds. Imagine that a dependent variable can have either of two values, A or B. If the probability of achieving outcome A is $p$, then the odds of achieving outcome $\mathrm{A}$ are $\mathrm{p} /(1-\mathrm{p})$. The odds ratio is the ratio of the odds that participants with one value of an attribute achieve outcome $\mathrm{A}$ and the odds that participants with another value of the attribute achieve outcome A. The outcome could be "achieving level 5 rather than level 4 on the $\mathrm{CAP}_{\mathrm{R}}$ " and the attribute could be "having a cochlear implant". If an explanatory variable is a covariate, the attribute is a difference of one in the value of the variable, such as an increase of 1 year of age or $1 \mathrm{~dB}$ of hearing level. If an explanatory variable is a factor, the attribute is the 
property that is present when a subject has one value of the factor and is absent when the subject has the other value (e.g. having received a cochlear implant vs. not having received a cochlear implant).

It is a requirement of regression analysis that covariates are linear in the (logit of the) dependent variable. Our data did not meet this requirement. Instead, most outcome measures increased steeply across low values of age but more gradually across higher values of age, and most outcome measures decreased gradually at low and high values of AHL but more steeply across the middle range of AHLs. Accordingly, we used the method described by Hosmer and Lemeshow (2000) to transform age and AHL to linearity. Several transforms were explored. The transform that best linearised age was a $2^{\text {nd }}$ order logarithmic function:

$$
A G E^{\prime}=y_{0}+a(\ln A G E)+b(\ln A G E)^{2}
$$

where $A G E$ is the untransformed value of age, $A G E^{\prime}$ is the transformed value, $a, b$, and $y_{o}$ are constants, and ( $\left.\ln A G E\right)$ is the natural logarithm of AGE. The transformation that best linearised AHL was a 3-parameter sigmoid:

$$
A H L^{\prime}=\frac{a}{1+e^{-\left(\frac{A H L-x_{0}}{b}\right)}}
$$

where $A H L$ is the untransformed value of AHL, $A H L$ ' is the transformed value, $a, b$, and $x_{o}$ are constants, and $e$ is the base of natural logarithms (2.718). Age and AHL were transformed separately for each analysis, yielding a different set of constants for each analysis. Their values are listed in the supplementary document (Stacey et al., Reference Note 1). An important consequence of transforming age and AHL is that the parameter values and odds ratios for these variables in the results of regression 
analyses refer to one unit of the transformed variable, not one unit of the untransformed variable.

\section{Functionally-equivalent, equivalent, and significant hearing levels}

We calculated functionally-equivalent, equivalent, and significant hearing levels from the results of Interaction Effects analyses. Imagine that a regression establishes that a dependent variable $(O)$ increases linearly with transformed age $\left(A G E^{\prime}\right)$, is greater for children whose hearing impairment started after the age of 3 years rather than at birth (ONS), declines linearly with transformed average hearing level (AHL'), and displays a significant interaction between $A H L^{\prime}$ and implantation (CI). The equation describing these relationships would take the form:

$O=a_{0}+\left(a_{1} \times A G E^{\prime}\right)+a_{2}($ if ONS $>3)+\left(a_{3} \times A H L^{\prime}\right)+a_{4}($ if $C I=$ 'yes' $)+a_{5} \times A H L '\left(\right.$ if $C I=$ ' yes' $\left.^{\prime}\right)$

where $a_{0}, a_{1}, a_{2}, a_{3}, a_{4}$, and $a_{5}$ are constants. The relationships between $A H L ', C I$, and $O$ can be isolated, while controlling the influence of $A G E^{\prime}$ and $O N S$, by considering only that part of the equation which involves $A H L$ ' and CI. For implanted children:

$$
O_{+C I}=\left(a_{3} \times A H L^{\prime}\right)+a_{4}+\left(a_{5} \times A H L^{\prime}\right)
$$

For non-implanted children:

$$
O_{-C I}=\left(a_{3} \times A H L^{\prime}\right)
$$

where $O_{+C I}$ is the component of $O$ that is contributed by the association of $O$ with $A H L^{\prime}$ and $C I$ for implanted children, and $O_{-C I}$ is the component of $O$ that is contributed by the association of $O$ with $A H L^{\prime}$ for non-implanted children. This decomposition is possible because the model is linear. If $O$ were plotted as a function of $A H L^{\prime}$ the lines for implanted and non-implanted children would scale together 
depending on the values of the variables $A G E^{\prime}$ and ONS.

The significant hearing level is estimated by calculating the 95 percent confidence interval of the difference between $O_{+C I}$ and $O_{-C I}$ as a function of $A H L$, and determining the lowest value of $A H L^{\prime}$ at which the confidence interval does not include zero (in the results of a multiple linear regression) or one (in the results of an ordinal logistic regression). The statistical package SAS (Freund \& Littell, 2000) provides tools for making these estimates. The equivalent hearing level is given by the value of $A H L$ ' at which $O_{+C I}$ equals $O_{-C I}$; i.e. $-a_{4} / a_{5}$. The functionally-equivalent hearing level is estimated for an implanted child as the value of $A H L$ ' for a nonimplanted child that corresponds to the level of outcome achieved by the implanted child. If $\mathrm{AHL}_{(+\mathrm{CI})}$ is the transformed AHL of an implanted child, the functionallyequivalent transformed AHL for that child, $A H L{ }_{(-C I)}$, is given by:

$$
A H L_{(-C I)}^{\prime}=a_{4} / a_{3}+A H L^{\prime}{ }_{(+C I)} \times\left(1+a_{5} / a_{3}\right)
$$

The value of $A H L{ }_{(+C I)}$ was calculated for each implanted child and an average value for each group of implanted children was obtained. Equation 2 was then used to calculate a functionally-equivalent transformed AHL for the group. Finally, Equation 3, which is the inverse of Equation 1, was used to convert the transformed AHL for the group to an untransformed value:

$$
A H L_{(-C I)}=x_{0}-b \ln \left(\frac{a}{A H L_{(+C I)}^{\prime}}-1\right)
$$

Values of functionally-equivalent, equivalent, and significant hearing levels can be estimated, depending on the strength and nature of the interaction between AHL and implantation. Figure 6 illustrates situations in which it was possible to 
estimate three, two, or only one of the values.

[FIGURE 6] 
Table 1: Definitions of explanatory variables.

\begin{tabular}{|c|c|}
\hline Definition of variable & Values \\
\hline 1. Age & Age of child when questionnaire was returned. \\
\hline 2. Average hearing level & $\begin{array}{l}\text { Average of unaided (pre-operative) hearing levels at } 0.5,1,2 \text {, } \\
\text { and } 4 \mathrm{kHz} \text { in the better hearing ear. }\end{array}$ \\
\hline 3. Age at onset of hearing impairment & $\begin{array}{l}\text { (i) At birth; (ii) between the ages of } 0 \text { and } 3 \text { years; (iii) older then } \\
3 \text { years of age. }\end{array}$ \\
\hline 4. Gender & (i) Male; (ii) female. \\
\hline $\begin{array}{l}\text { 5. Number of disabilities in addition to } \\
\text { hearing impairment }\end{array}$ & (i) None; (ii) one; (iii) two or more. \\
\hline $\begin{array}{l}\text { 6. Parental occupational skill level } \\
\text { (classification of skill/training required } \\
\text { for parent's occupation) }\end{array}$ & (i) 1 (the lowest level); (ii) 2; (iii) 3; (i) 4 (the highest level). \\
\hline 7. Ethnicity & (i) Other; (ii) White. \\
\hline 8. Parental hearing status & $\begin{array}{l}\text { (i) No hearing difficulty experienced by either parent; (ii) at least } \\
\text { some hearing difficulty experienced by at least one parent. }\end{array}$ \\
\hline
\end{tabular}

(Continued on next sheet.) 
Table 1 (continued).

\begin{tabular}{ll}
\hline 9. Cochlear implantation & (i) Implanted before the age of 5 years, used implants for less \\
than 2 years $(<5,<2)$ \\
(ii) Implanted before the age of 5 years, used implants for \\
between 2 and 4 years $(<5, \geq 2<4)$ \\
(iii) Implanted before the age of 5 years, used implants for 4 or \\
more years $(<5, \geq 4)$ \\
(iv) Implanted at or after the age of 5 years, used implants for \\
less than 2 years $(\geq 5,<2)$ \\
(v) Implanted at or after the age of 5 years, used implants for \\
between 2 and 4 years $(\geq 5, \geq 2<4)$ \\
(vi) Implanted at or after the age of 5 years, used implants for 4 \\
or more years $(\geq 5, \geq 4)$ \\
(vii) Not implanted \\
(i) Spoken language only. \\
(ii) BSL, alone or in conjunction with another mode. \\
(10. Mode of communication used in $S S$, alone or in conjunction with another mode. \\
(iv) Makaton, alone or in conjunction with another mode. \\
(v) Alternative forms \\
\hline
\end{tabular}


Table 2: Categorisation of questions into domains, sections, and areas of functioning. Parents (N): The number of parents who completed each question. Teachers $(\mathrm{N})$ : The number of teachers who completed each question. Analyses: The type of statistical analysis applied to the outcome measure. (OLR: Ordinal logistic regression. MLR: Multiple linear regression. CPCA: Categorical principal components analysis.)

(Continued on next sheet.) 
Table 2 (continued).

\begin{tabular}{|c|c|c|c|c|c|}
\hline Domain & Section & Area of functioning & $\begin{array}{l}\text { Parents } \\
(\mathrm{N})\end{array}$ & $\begin{array}{l}\text { Teachers } \\
(\mathrm{N})\end{array}$ & Analyses \\
\hline $\begin{array}{l}\text { Auditory } \\
\text { performance }\end{array}$ & $\begin{array}{l}\text { Auditory } \\
\text { performance }\end{array}$ & Auditory receptive capabilities & 2558 & 2157 & OLR \\
\hline \multirow{2}{*}{$\begin{array}{l}\text { Communication } \\
\text { skills }\end{array}$} & \multirow[t]{2}{*}{ Speech } & Speech perception & 2435 & 1916 & OLR \\
\hline & & Speech intelligibility & 2413 & 1907 & OLR \\
\hline \multirow{14}{*}{$\begin{array}{l}\text { Educational } \\
\text { achievements }\end{array}$} & \multirow{6}{*}{$\begin{array}{l}\text { Academic } \\
\text { abilities }\end{array}$} & Reading & 2487 & 2131 & \multirow{6}{*}{$\begin{array}{l}\text { CPCA \& } \\
\text { MLR }\end{array}$} \\
\hline & & Writing & 2529 & 2145 & \\
\hline & & Number & 2543 & 2165 & \\
\hline & & Time & 2537 & 2145 & \\
\hline & & Money & 2528 & 2128 & \\
\hline & & Measurement & 2480 & 2057 & \\
\hline & \multirow{4}{*}{$\begin{array}{l}\text { Key-stage } \\
\text { attainments }\end{array}$} & KS Reading & - & 974 & \multirow{4}{*}{$\begin{array}{c}\text { CPCA \& } \\
\text { MLR }\end{array}$} \\
\hline & & KS Writing & - & 943 & \\
\hline & & KS Maths & - & 1109 & \\
\hline & & KS Science & - & 1020 & \\
\hline & Reading age & Reading & - & 1082 & MLR \\
\hline & \multirow{3}{*}{$\begin{array}{l}\text { Participation and } \\
\text { engagement }\end{array}$} & Attention in a small class & - & 1950 & \multirow{3}{*}{$\begin{array}{c}\text { CPCA \& } \\
\text { MLR }\end{array}$} \\
\hline & & Understanding instruction & - & 2177 & \\
\hline & & Engagement in group discussions & - & 2111 & \\
\hline \multirow[t]{15}{*}{ Quality of life } & \multirow[t]{7}{*}{ Child and family } & Willingness to go to school & 2825 & - & \multirow{7}{*}{$\begin{array}{c}\text { CPCA \& } \\
\text { MLR }\end{array}$} \\
\hline & & Friends at school & 2808 & - & \\
\hline & & Friends out of school & 2796 & - & \\
\hline & & Feelings: (8 questions) & $2342-2561$ & - & \\
\hline & & Satisfaction: (6 questions) & $2613-2673$ & - & \\
\hline & & Concern: (7 questions) & $2707-2796$ & - & \\
\hline & & Affect on family life: (6 questions) & $2767-2790$ & - & \\
\hline & \multirow{2}{*}{$\begin{array}{l}\text { Help (shop and } \\
\text { friend) }\end{array}$} & Buying from shop & 2499 & - & \multirow{2}{*}{$\begin{array}{c}\text { CPCA \& } \\
\text { MLR }\end{array}$} \\
\hline & & Inviting friend to visit & 2325 & - & \\
\hline & \multirow{3}{*}{$\begin{array}{l}\text { Help (telephone } \\
\text { and travel) }\end{array}$} & Using friend's telephone & 1407 & - & \multirow{3}{*}{$\begin{array}{c}\text { CPCA \& } \\
\text { MLR }\end{array}$} \\
\hline & & Using public telephone & 809 & - & \\
\hline & & Using public transport & 902 & - & \\
\hline & \multirow[t]{3}{*}{ Socialisation } & Friends with deaf children & - & 1786 & \multirow{3}{*}{$\begin{array}{c}\text { CPCA \& } \\
\text { MLR }\end{array}$} \\
\hline & & Friends with hearing children & - & 2116 & \\
\hline & & Happy at school & - & 2197 & \\
\hline
\end{tabular}


Table 3: Number of implanted children in the analyses of data from parents and from teachers, categorised in the six groups formed by the intersection of two ages at implantation and three durations of implant use.

\begin{tabular}{ccccc}
\hline & & \multicolumn{3}{c}{ Duration of use } \\
\cline { 2 - 4 } & & $<2$ yrs & $\geq 2,<4$ yrs & $\geq 4$ yrs \\
\hline \multirow{3}{*}{$\begin{array}{c}\text { Age at } \\
\text { implantation }\end{array}$} & $<5$ yrs & Parent $\mathrm{N}=80$ & Parent $\mathrm{N}=90$ & Parent $\mathrm{N}=98$ \\
\cline { 2 - 4 } & & Teacher $\mathrm{N}=39$ & Teacher $\mathrm{N}=103$ & Teacher $\mathrm{N}=102$ \\
& & & & \\
& & & & \\
& & Parent $\mathrm{N}=62$ & Parent $\mathrm{N}=65$ & Parent $\mathrm{N}=73$ \\
& & Teacher $\mathrm{N}=30$ & Teacher $\mathrm{N}=45$ & Teacher $\mathrm{N}=57$ \\
\hline
\end{tabular}


Table 4: Explanatory variables for six groups of implanted children, non-implanted children, and the total group. Values are for children for whom data were reported by parents. $(\mathrm{N})$ number of children for whom each variable was available. (SD) standard deviation.

\begin{tabular}{|c|c|c|c|c|c|c|c|c|}
\hline \multirow[t]{5}{*}{ Variables } & \multicolumn{6}{|c|}{ Age at implantation (years) } & \multirow[t]{4}{*}{ No Implant } & \multirow[t]{4}{*}{ Total } \\
\hline & \multicolumn{3}{|c|}{$<5$} & \multicolumn{3}{|c|}{$\geq 5$} & & \\
\hline & \multicolumn{6}{|c|}{ Duration of use (years) } & & \\
\hline & $<2$ & $\geq 2,<4$ & $\geq 4$ & $<2$ & $\geq 2,<4$ & $\geq 4$ & & \\
\hline & $\mathrm{N}=80$ & $\mathrm{~N}=90$ & $\mathrm{~N}=98$ & $\mathrm{~N}=62$ & $\mathrm{~N}=65$ & $\mathrm{~N}=73$ & $N=2390$ & $\mathrm{~N}=2858$ \\
\hline $\begin{array}{r}\text { Mean } \\
\text { SD } \\
\text { Median } \\
\text { Inter-Quartile Range } \\
\text { Range }\end{array}$ & $\begin{array}{c}3.6 \\
0.7 \\
3.5 \\
3.1-4.3 \\
2.0-4.9\end{array}$ & $\begin{array}{c}3.4 \\
0.9 \\
3.4 \\
2.8-4.2 \\
1.1-4.9 \\
\end{array}$ & $\begin{array}{c}3.5 \\
0.8 \\
3.6 \\
3.1-4.9 \\
1.6-4.9\end{array}$ & $\begin{array}{c}9.9 \\
3.4 \\
9.5 \\
7.2-12.4 \\
5.0-17.7\end{array}$ & $\begin{array}{c}7.3 \\
2.4 \\
6.5 \\
5.8-8.3 \\
5.0-15.8\end{array}$ & $\begin{array}{c}7.8 \\
1.9 \\
7.4 \\
6.2-9.2 \\
5.0-12.6 \\
\end{array}$ & & \\
\hline $\begin{array}{rr}\text { Duration of use } & \text { Mean } \\
\text { SD } \\
\text { Median } \\
\text { Inter-Quartile Range } \\
\text { Range } \\
\end{array}$ & $\begin{array}{l}1.3 \\
0.5 \\
1.3 \\
1.0-1.7 \\
0.1-2.0 \\
\end{array}$ & $\begin{array}{c}2.9 \\
0.6 \\
2.9 \\
2.3-3.4 \\
2.0-4.0 \\
\end{array}$ & $\begin{array}{c}5.8 \\
1.4 \\
5.4 \\
4.8-6.6 \\
4.0-10.5 \\
\end{array}$ & $\begin{array}{c}1.1 \\
0.6 \\
1.1 \\
0.6-1.6 \\
0.0-2.0 \\
\end{array}$ & $\begin{array}{l}2.9 \\
0.6 \\
2.9 \\
2.5-3.5 \\
2.0-4.0 \\
\end{array}$ & $\begin{array}{c}6.0 \\
1.5 \\
5.9 \\
4.9-6.8 \\
4.0-9.9 \\
\end{array}$ & & \\
\hline $\begin{array}{rr}\text { Average hearing level }(\mathrm{dB}) & \text { Mean } \\
\mathrm{SD} \\
\text { Median } \\
\text { Inter-Quartile Range } \\
\text { Range }\end{array}$ & $\begin{array}{c}111.0 \\
11.7 \\
110.0 \\
102-120.5 \\
80-130\end{array}$ & $\begin{array}{c}112.8 \\
11.3 \\
111.5 \\
105-120 \\
86-130\end{array}$ & $\begin{array}{c}118.5 \\
9.8 \\
120.0 \\
111-128 \\
89-140\end{array}$ & $\begin{array}{l}111.4 \\
9.3 \\
110.0 \\
106-119 \\
92-130\end{array}$ & $\begin{array}{l}116.2 \\
9.2 \\
117.0 \\
110-122 \\
86-130\end{array}$ & $\begin{array}{l}117.5 \\
8.7 \\
117.0 \\
110-126 \\
100-130\end{array}$ & $\begin{array}{c}88.4 \\
21.5 \\
92.0 \\
76-104 \\
4-140\end{array}$ & $\begin{array}{c}92.3 \\
22.2 \\
97.0 \\
79-108 \\
4-140\end{array}$ \\
\hline $\begin{array}{r}\text { Mean } \\
\text { SD } \\
\text { Median } \\
\text { Inter-Quartile Range } \\
\text { Range }\end{array}$ & $\begin{array}{c}5.0 \\
0.8 \\
4.8 \\
4.3-5.5 \\
3.3-6.7\end{array}$ & $\begin{array}{c}6.3 \\
1.1 \\
6.4 \\
5.5-7.2 \\
4.1-8.8\end{array}$ & $\begin{array}{c}9.3 \\
1.6 \\
9.1 \\
8.3-10.3 \\
5.9-14.0\end{array}$ & $\begin{array}{c}11.0 \\
3.3 \\
10.6 \\
8.0-13.4 \\
5.9-18.5\end{array}$ & $\begin{array}{c}10.2 \\
2.6 \\
9.5 \\
8.4-11.1 \\
7.2-19.5\end{array}$ & $\begin{array}{c}13.8 \\
2.5 \\
13.3 \\
11.7-15.9 \\
9.5-19.9\end{array}$ & $\begin{array}{c}12.1 \\
4.1 \\
12.3 \\
8.8-15.5 \\
3.4-20.6\end{array}$ & $\begin{array}{c}11.6 \\
4.2 \\
11.7 \\
8.2-15.0 \\
3.3-20.6\end{array}$ \\
\hline
\end{tabular}

(Continued on next sheet.) 
(Table 4, continued.)

\begin{tabular}{|c|c|c|c|c|c|c|c|c|c|}
\hline & & $\%$ & $\%$ & $\%$ & $\%$ & $\%$ & $\%$ & $\%$ & $\%$ \\
\hline \multirow{4}{*}{$\begin{array}{l}\text { Age at onset } \\
\mathrm{N}=2825\end{array}$} & Birth & 87.5 & 81.1 & 66.3 & 85.5 & 70.8 & 56.2 & 79.3 & 78.5 \\
\hline & $>0, \leq 3$ yrs & 11.3 & 15.6 & 33.7 & 11.3 & 18.5 & 28.8 & 13.6 & 14.7 \\
\hline & $>3$ yrs & 1.3 & 3.3 & 0.0 & 3.2 & 10.8 & 15.1 & 5.7 & 5.6 \\
\hline & Missing & 0.0 & 0.0 & 0.0 & 0.0 & 0.0 & 0.0 & 1.4 & 1.2 \\
\hline Gender & Male & 60.0 & 63.3 & 44.9 & 40.3 & 52.3 & 53.4 & 55.0 & 54.4 \\
\hline$N=2858$ & Female & 40.0 & 36.7 & 55.1 & 59.7 & 47.7 & 46.6 & 45.0 & 45.6 \\
\hline \multirow{2}{*}{$\begin{array}{l}\text { Number of } \\
\text { disabilities }\end{array}$} & None & 78.8 & 78.9 & 71.4 & 77.4 & 70.8 & 67.1 & 63.6 & 65.3 \\
\hline & One & 16.3 & 8.9 & 16.3 & 17.7 & 18.5 & 23.3 & 16.8 & 16.7 \\
\hline$N=2858$ & Two plus & 5.0 & 12.2 & 12.2 & 4.8 & 10.8 & 9.6 & 19.7 & 18.0 \\
\hline \multirow{5}{*}{$\begin{array}{l}\text { Parental } \\
\text { occupational skill } \\
\text { level } \\
\mathrm{N}=2822\end{array}$} & Level 4 'highest' & 25.0 & 17.8 & 36.7 & 27.4 & 38.5 & 26.0 & 20.4 & 21.7 \\
\hline & Level 3 & 43.8 & 42.2 & 39.8 & 32.3 & 27.7 & 37.0 & 37.3 & 37.4 \\
\hline & Level 2 & 20.0 & 28.9 & 16.3 & 29.0 & 21.5 & 21.9 & 27.4 & 26.6 \\
\hline & Level 1 'lowest' & 10.0 & 11.1 & 6.1 & 11.3 & 10.8 & 12.3 & 13.6 & 13.1 \\
\hline & Missing & 1.3 & 0.0 & 1.0 & 0.0 & 1.5 & 2.7 & 1.3 & 1.3 \\
\hline \multirow{2}{*}{$\begin{array}{l}\text { Parental hearing } \\
\text { status } \\
\mathrm{N}=2857\end{array}$} & No difficulties & 93.8 & 94.4 & 94.9 & 95.2 & 96.9 & 91.8 & 86.9 & 88.2 \\
\hline & $\begin{array}{l}\text { At least some hearing } \\
\text { difficulty }\end{array}$ & 6.3 & 5.6 & 5.1 & 4.8 & 3.1 & 8.2 & 13.1 & 11.8 \\
\hline \multirow{2}{*}{$\begin{array}{l}\text { Ethnicity } \\
N=2829\end{array}$} & White & 88.6 & 93.3 & 88.8 & 86.9 & 87.5 & 94.5 & 89.1 & 89.3 \\
\hline & Other & 11.4 & 6.7 & 11.2 & 13.1 & 12.5 & 5.5 & 10.9 & 10.7 \\
\hline \multirow{7}{*}{$\begin{array}{l}\text { Communication } \\
\text { during teaching } \\
\mathrm{N}=1957\end{array}$} & Spoken only & 30.0 & 35.6 & 39.8 & 51.6 & 35.4 & 24.7 & 39.4 & 38.8 \\
\hline & BSL Only & 1.3 & 0.0 & 0.0 & 0.0 & 0.0 & 1.4 & 0.4 & 0.4 \\
\hline & BSL \& Other & 22.5 & 21.1 & 21.4 & 17.7 & 18.5 & 28.8 & 14.6 & 15.8 \\
\hline & Element of SSE & 17.5 & 13.3 & 14.3 & 12.9 & 6.2 & 9.6 & 7.2 & 8.0 \\
\hline & Element of Makaton & 1.3 & 1.1 & 0.0 & 0.0 & 0.0 & 0.0 & 2.9 & 2.5 \\
\hline & Alternative forms & 5.0 & 4.4 & 0.0 & 0.0 & 0.0 & 1.4 & 3.2 & 3.0 \\
\hline & Missing & 22.5 & 24.4 & 24.5 & 17.7 & 40.0 & 34.2 & 32.4 & 31.5 \\
\hline
\end{tabular}

Table 5: Associations between cochlear implantation and outcome measures from Main Effects analyses. Where the form of analysis was ordinal 
logistic regression $(\mathrm{O})$, entries are odds ratios. Where the form of analysis was multiple linear regression (M), entries are parameter values. Informants were either parents $(\mathrm{P})$ or teachers $(\mathrm{T})$. Where an entry is underlined, the outcome measure was significantly poorer when average hearing level was less favourable. Where entries for educational achievements and quality of life are emboldened, there was no association between implantation and data being missing. Asterisks indicate the significance levels of odds ratios and parameter values $(* \mathrm{p}<0.05 ; * * \mathrm{p}<0.01 ; * * * \mathrm{p}<0.001)$.

\section{(Continued on next sheet.)}




\begin{tabular}{|c|c|c|c|c|c|c|c|c|c|}
\hline & & \multirow{3}{*}{$\begin{array}{l}\text { Form of } \\
\text { analysis }\end{array}$} & \multirow[t]{3}{*}{ Informants } & \multirow{2}{*}{\multicolumn{3}{|c|}{$\begin{array}{l}\text { Implanted before } \mathbf{5} \text { years of age } \\
\text { Time since implantation (years) }\end{array}$}} & \multicolumn{3}{|c|}{ Implanted after 5 years of age } \\
\hline & & & & & & & Time sin & implantatio & (years) \\
\hline & & & & $<2$ & $\geq 2$ to $<4$ & $\geq 4$ & $<2$ & $\geq 2$ to $<4$ & $\geq 4$ \\
\hline \multirow{2}{*}{$\begin{array}{l}\text { Auditory } \\
\text { performance }\end{array}$} & \multirow[t]{2}{*}{ Auditory receptive capabilities } & $\mathrm{O}$ & $\mathrm{P}$ & $\underline{4.290^{* * *}}$ & $17.945^{\star * *}$ & $\underline{74.351^{* * *}}$ & $\underline{5.159^{* *}}$ & $\underline{12.889^{* * *}}$ & $\underline{14.982^{* * *}}$ \\
\hline & & $\mathrm{O}$ & $\mathrm{T}$ & $\underline{8.056^{* *}}$ & $\underline{9.862^{* * *}}$ & $\underline{79.074^{* * *}}$ & $\underline{12.877^{*}}$ & $\underline{13.858^{* * *}}$ & $\underline{6.007^{* * *}}$ \\
\hline \multirow{6}{*}{$\begin{array}{l}\text { Spoken } \\
\text { communication } \\
\text { skills }\end{array}$} & \multirow[t]{2}{*}{ Use of spoken language } & $\mathrm{O}$ & $P$ & $\underline{3.144^{* *}}$ & $\underline{13.474^{* * *}}$ & $\underline{75.069^{* * *}}$ & $\underline{3.484^{* *}}$ & $\underline{9.642^{* * *}}$ & $\underline{13.364^{* * *}}$ \\
\hline & & O & $\mathrm{T}$ & $\underline{7.678^{* *}}$ & $\underline{10.992^{* * *}}$ & $\underline{94.062^{* * *}}$ & $\underline{12.613}$ & $\underline{13.445^{\star * *}}$ & $\underline{6.218^{* * *}}$ \\
\hline & \multirow[t]{2}{*}{ Perception of spoken language } & $\mathrm{O}$ & $P$ & $\underline{2.148^{* *}}$ & $\underline{7.321^{* * *}}$ & $\underline{12.551^{* * *}}$ & $\underline{3.861^{* * *}}$ & $\underline{3.881^{* * *}}$ & $2.649^{* * *}$ \\
\hline & & $\mathrm{O}$ & $\mathrm{T}$ & $\underline{1.778}$ & $\underline{3.443 * * *}$ & $\underline{9.481^{* * *}}$ & $\underline{4.041^{* * *}}$ & $\underline{3.679 * * *}$ & $2.355^{* *}$ \\
\hline & \multirow[t]{2}{*}{ Production of spoken language } & $\mathrm{O}$ & $P$ & $\underline{2.145^{*}}$ & $\underline{2.648^{* * *}}$ & $\underline{3.191^{* * *}}$ & $\underline{1.915^{*}}$ & $\underline{0.999}$ & $\underline{0.748}$ \\
\hline & & $\mathrm{O}$ & $\mathrm{T}$ & 1.031 & 1.577 & $2.539^{\star * *}$ & 1.690 & $\underline{1.065}$ & $\underline{0.732}$ \\
\hline \multirow{5}{*}{$\begin{array}{l}\text { Educational } \\
\text { achievements }\end{array}$} & \multirow[t]{2}{*}{ Academic abilities } & M & $\mathrm{P}$ & $\underline{-0.039}$ & $\underline{-0.234^{\star *}}$ & $\underline{0.077}$ & $\underline{0.022}$ & $\underline{0.063}$ & $\underline{0.137}$ \\
\hline & & M & $\mathrm{T}$ & $\underline{-0.004}$ & $\underline{-0.090}$ & $\underline{0.185^{*}}$ & $\underline{0.104}$ & $\underline{0.103}$ & $\underline{0.178}$ \\
\hline & Key stage attainments & M & $\mathrm{T}$ & $\underline{-0.124}$ & $\underline{0.329}$ & $\underline{-0.098}$ & $\underline{0.235}$ & $\underline{-0.283}$ & $\underline{-0.196}$ \\
\hline & Reading age & M & $\mathrm{T}$ & $\underline{0.321}$ & $\underline{1.721^{* *}}$ & $\underline{0.659}$ & $\underline{0.332}$ & $\underline{0.452}$ & $\underline{-0.545}$ \\
\hline & Participation and engagement & M & $\mathrm{T}$ & $\underline{-0.108}$ & $\underline{-0.034}$ & $\underline{0.224^{*}}$ & $\underline{0.195}$ & $\underline{0.139}$ & $\underline{0.190}$ \\
\hline \multirow[t]{10}{*}{ Quality of life } & Disruption & $M$ & $P$ & $\underline{0.226}$ & $\underline{0.116}$ & $\underline{0.166}$ & $\underline{0.005}$ & $\underline{-0.101}$ & $\underline{-0.200}$ \\
\hline & Satisfaction & M & $\mathrm{P}$ & -0.205 & -0.081 & -0.018 & 0.070 & $0.455^{\star \star}$ & 0.151 \\
\hline & Feelings & M & $\mathrm{P}$ & 0.038 & 0.014 & -0.086 & 0.206 & 0.017 & 0.082 \\
\hline & Future concerns & M & $\mathrm{P}$ & 0.144 & 0.254 & $0.355^{\star *}$ & $0.320^{*}$ & 0.204 & 0.033 \\
\hline & Friendships & M & $\mathrm{P}$ & -0.017 & 0.055 & 0.188 & -0.049 & 0.152 & 0.007 \\
\hline & Behaviour & M & $P$ & $\underline{-0.155}$ & $\underline{0.156}$ & $\underline{0.274}$ & $\underline{0.011}$ & $\underline{0.038}$ & $\underline{0.143}$ \\
\hline & Well being & M & $P$ & 0.177 & 0.126 & 0.194 & -0.150 & 0.005 & 0.052 \\
\hline & Help (shop and friend) & M & $P$ & $\underline{-0.025}$ & $\underline{0.179}$ & $\underline{0.233^{*}}$ & $\underline{-0.101}$ & $\underline{0.200}$ & $\underline{-0.127}$ \\
\hline & Help (phone and travel) & M & $P$ & $\ddagger$ & $\ddagger$ & $\ddagger$ & $\ddagger$ & $\ddagger$ & $\ddagger$ \\
\hline & Sociability & $M$ & $\mathrm{~T}$ & 0.098 & 0.083 & $0.277^{*}$ & 0.259 & 0.067 & $0.395^{*}$ \\
\hline
\end{tabular}

\footnotetext{
${ }^{\ddagger}$ Too few data for analysis
} 
Table 6: Mean average hearing levels (AHL), functionally-equivalent hearing levels (FE), equivalent hearing levels (E), and significant hearing levels $(\mathrm{S})$ in $\mathrm{dB}$ calculated for five outcome measures and for six groups of children with cochlear implants. The mean AHL is the average for those children for whom each outcome was reported.

(Continued on next sheet.) 
(Table 6, continued.)

\begin{tabular}{|c|c|c|c|c|c|c|c|c|c|c|c|c|c|}
\hline \multirow[b]{2}{*}{ Outcome } & \multirow[b]{2}{*}{ Informants } & \multicolumn{12}{|c|}{ Implanted before the age of 5 years } \\
\hline & & AHL & FE & $\mathrm{E}$ & $\mathbf{S}$ & AHL & FE & E & $\mathbf{s}$ & AHL & FE & $\mathbf{E}$ & $\mathbf{S}$ \\
\hline \multirow{2}{*}{$\begin{array}{l}\text { Speech } \\
\text { perception }\end{array}$} & Parents & 111 & 100 & 96 & 105 & 113 & 89 & 76 & 95 & 118 & 87 & $\alpha$ & 95 \\
\hline & Teachers & 109 & 100 & 100 & 108 & 113 & 97 & 98 & 104 & 116 & 89 & 65 & 97 \\
\hline $\begin{array}{l}\text { Speech } \\
\text { intelligibility }\end{array}$ & Parents & 110 & 95 & 98 & 104 & 112 & 94 & 94 & 101 & 118 & 94 & 100 & 105 \\
\hline $\begin{array}{l}\text { Academic } \\
\text { abilities }\end{array}$ & Teachers & 109 & 83 & $\alpha$ & $\beta$ & 113 & 89 & $\alpha$ & $\beta$ & 116 & 87 & 96 & 112 \\
\hline Help & Parents & 113 & 113 & $\alpha$ & $\beta$ & 113 & 93 & $\alpha$ & 114 & 118 & 91 & $\alpha$ & 112 \\
\hline
\end{tabular}


(Table 6, continued.)

\begin{tabular}{|c|c|c|c|c|c|c|c|c|c|c|c|c|c|}
\hline \multirow[b]{2}{*}{ Outcome } & \multirow[b]{2}{*}{ Informants } & \multicolumn{12}{|c|}{ Implanted at or after the age of 5 years } \\
\hline & & AHL & FE & $\mathbf{E}$ & $\mathbf{s}$ & AHL & FE & $\mathbf{E}$ & $\mathbf{S}$ & AHL & FE & $\mathbf{E}$ & $\mathbf{S}$ \\
\hline \multirow{2}{*}{$\begin{array}{l}\text { Auditory } \\
\text { performance }\end{array}$} & Parents & 111 & 100 & 91 & 102 & 117 & 95 & 105 & 118 & 118 & 97 & 98 & 107 \\
\hline & Teachers & 111 & $<80$ & 88 & 103 & 115 & $<80$ & 101 & 117 & 117 & 104 & $\alpha$ & 99 \\
\hline \multirow{2}{*}{$\begin{array}{l}\text { Speech } \\
\text { perception }\end{array}$} & Parents & 111 & 95 & 76 & 100 & 117 & 98 & 95 & 106 & 118 & 102 & 99 & 109 \\
\hline & Teachers & 111 & 95 & 78 & 104 & 115 & 98 & $\alpha$ & 103 & 117 & 104 & $\alpha$ & 106 \\
\hline $\begin{array}{l}\text { Speech } \\
\text { intelligibility }\end{array}$ & Parents & 111 & 97 & $\alpha$ & 103 & 116 & 111 & $\alpha$ & $\beta$ & 117 & $>130$ & $\alpha$ & $\beta$ \\
\hline $\begin{array}{l}\text { Academic } \\
\text { abilities }\end{array}$ & Teachers & 111 & 95 & $\alpha$ & $\beta$ & 115 & 104 & $\alpha$ & $\beta$ & 118 & 94 & $\alpha$ & 117 \\
\hline Help & Parents & 111 & $>130$ & $\alpha$ & $\beta$ & 116 & 108 & $\alpha$ & $\beta$ & 118 & $>130$ & $\alpha$ & $\beta$ \\
\hline
\end{tabular}


Table 6 (continued).

$\alpha$ Could not be calculated (no significant interaction between implantation and average hearing level).

$\beta$ Could not be calculated (no significant hearing level at or below $130 \mathrm{~dB}$ ).

$\gamma$ Significant negative effect of implantation over a restricted range of hearing levels.

$\delta$ Significant positive effect of implantation over a restricted range of average hearing levels. 
Table 7: Significance of explanatory variables in multiple linear regression analyses of outcomes in the domain of educational achievements. Analysis 1 included the listed variables plus the variables related to cochlear implantation whose levels of significance are given in Table 5. Analysis 2 analysed the residual variance from Analysis 1 according to the mode of communication used in teaching. Results for Analysis 2 include the percentages of children with each mode of communication for whom the outcome was reported. (***, $\mathrm{p}<0.001 ;{ }^{* *}, \mathrm{p}<0.01 ; *, \mathrm{p}<0.05 ;-$, not significant). ( $\mathrm{r}_{1}{ }^{2}$, adjusted $\mathrm{r}$-squared of Analysis $1 . \mathrm{r}_{2}^{2}$, adjusted r-squared of Analysis 2).

(Continued on next sheet.) 
(Table 7, continued.)

\begin{tabular}{|c|c|c|c|c|c|}
\hline Analysis & Explanatory variable & $\begin{array}{c}\text { Academic } \\
\text { abilities } \\
\text { (Parents) }\end{array}$ & $\begin{array}{l}\text { Academic } \\
\text { abilities } \\
\text { (Teachers) }\end{array}$ & $\begin{array}{l}\text { Reading } \\
\text { Age } \\
\text { (Teachers) }\end{array}$ & $\begin{array}{l}\text { Key-stage } \\
\text { Attainments } \\
\text { (Teachers) }\end{array}$ \\
\hline \multirow[t]{13}{*}{1} & ONS: $3+$ vs. birth & $* * *$ & * & * & $* *$ \\
\hline & ONS: $0-3$ vs. birth & - & - & - & - \\
\hline & DIS: None vs. 2+ & $* * *$ & $* * *$ & $* * *$ & $* * *$ \\
\hline & DIS: None vs. 1 & $* * *$ & $* * *$ & $* * *$ & $* *$ \\
\hline & POSL: 1 vs. 4 & $* * *$ & $* * *$ & $* * *$ & $* * *$ \\
\hline & POSL: 1 vs. 3 & $* * *$ & $* * *$ & $* * *$ & $* * *$ \\
\hline & POSL: 1 vs. 2 & ** & ** & $* *$ & ** \\
\hline & GEND: F vs M & ** & * & - & - \\
\hline & $\begin{array}{l}\text { PHS: Some vs. No } \\
\text { Problems }\end{array}$ & $* *$ & - & - & * \\
\hline & ETH: White vs. Other & - & - & - & * \\
\hline & Greater AHL & $* * *$ & $* * *$ & $* * *$ & $* * *$ \\
\hline & Older AGE & $* * *$ & $* * *$ & $* * *$ & $* * *$ \\
\hline & $\mathrm{R}_{1}{ }^{2}$ & 0.704 & 0.650 & 0.392 & 0.443 \\
\hline \multirow[t]{7}{*}{2} & Spoken only vs. ... & $(8 \%)$ & $(9 \%)$ & $(43 \%)$ & $(58 \%)$ \\
\hline & ... BSL only & $-(30 \%)$ & $-\quad(10 \%)$ & $-\quad(70 \%)$ & $-\quad(90 \%)$ \\
\hline & $\ldots$ BSL and other & $* * * \quad(15 \%)$ & $* * * \quad(10 \%)$ & $* * * \quad(61 \%)$ & $* * * \quad(65 \%)$ \\
\hline & ... SSE, SE, and other & * $\quad(10 \%)$ & $* * * \quad(7 \%)$ & $* * *(51 \%)$ & $* * * \quad(59 \%)$ \\
\hline & ... Makaton & ${ }^{* * *}(92 \%)$ & $* * * \quad(54 \%)$ & ${ }^{* * *}(86 \%)$ & ** $\quad(97 \%)$ \\
\hline & ... Special modes & $* * * \quad(61 \%)$ & $* * * \quad(39 \%)$ & $* * * \quad(83 \%)$ & $-\quad(89 \%)$ \\
\hline & $\mathrm{R}_{2}^{2}$ & 0.052 & 0.124 & 0.097 & 0.051 \\
\hline
\end{tabular}




\section{Figure Captions}

Figure 1: A cascade of benefits that can be hypothesised to flow from the provision of cochlear implants to young deaf children. [Reproduced from Summerfield and Marshall (1999), with permission.]

Figure 2: Odds ratios for explanatory variables from a Main Effects analysis of skill in the perception of spoken language (Speech perception). Filled and open circles plot results from analyses of data reported by parents and teachers, respectively.

Figure 3: Odds ratios for the difference in skill in the perception of spoken language (Speech perception) between implanted and non-implanted children as a function of AHL for 6 groups of implanted children plotted as heavy continuous lines. Heavy dashed lines plot 95 percent confidence limits. Equivalent hearing levels are marked 'e'. Significant hearing levels are marked 's'. Data were reported by parents.

Figure 4: Median rank importance as measured by level of statistical significance (bars, referenced to the left-hand axis) and percentage of significant associations $(\mathrm{p}<0.05)$ (dashed lines, referenced to the right-hand axis) for explanatory variables in analyses of Auditory performance and Communication skills (Left-hand panel) and Academic achievement and Quality of life (Right-hand panel). Error bars plot 95 percent confidence intervals of median ranks. Counts of numbers of significant associations are 
out of 8 (Left-hand panel) and 14 (Right-hand panel ). Bars for six groups of implanted children are coloured grey.

Figure 5: Consequences of controlling an increasing number of explanatory variables on the association between cochlear implantation and auditory receptive capabilities (Panel $\mathrm{A}$, data from parents, plotted as odds ratios) and between cochlear implantation and academic abilities (Panel B, data from teachers, plotted as parameters). Results are shown for two groups of implanted children: (filled circles) implanted before the age of $5(<5)$, used implants for 4 years or more $(\geq 4)$; (open circles) $\geq 5, \geq 4$. Each line shows how the estimate of the effect of cochlear implantation changes as each variable denoted on the horizontal axis is added into the analysis. (CI) cochlear implantation; (AHL) average hearing level; (AGE) current age; (DIS) presence of other disabilities; (ONS) age of onset of hearing impairment; (SEG) parental occupational skill level; (ETH) ethnicity; (GND) gender; (PHS) parental hearing status. Dashed lines mark an odds ratio of one (Panel A) and a parameter value of zero (Panel B). Error bars plot 95 percent confidence intervals.

Figure 6: Three relationships between AHL and an outcome score for implanted children (heavy dotted lines in Panels A, B, and C) and nonimplanted children (heavy solid lines in Panels A, B, and C). Panels D, E, and F plot the difference in score between implanted and non-implanted children, with the grey area marking the 95 percent confidence interval of the 
difference. Functionally-equivalent hearing levels are labelled ' $\mathrm{f}$ ' in Panels A and B. The equivalent hearing level is labelled 'e' in Panel D. Significant hearing levels are labelled 's' in Panels E and F. 
Figure 1

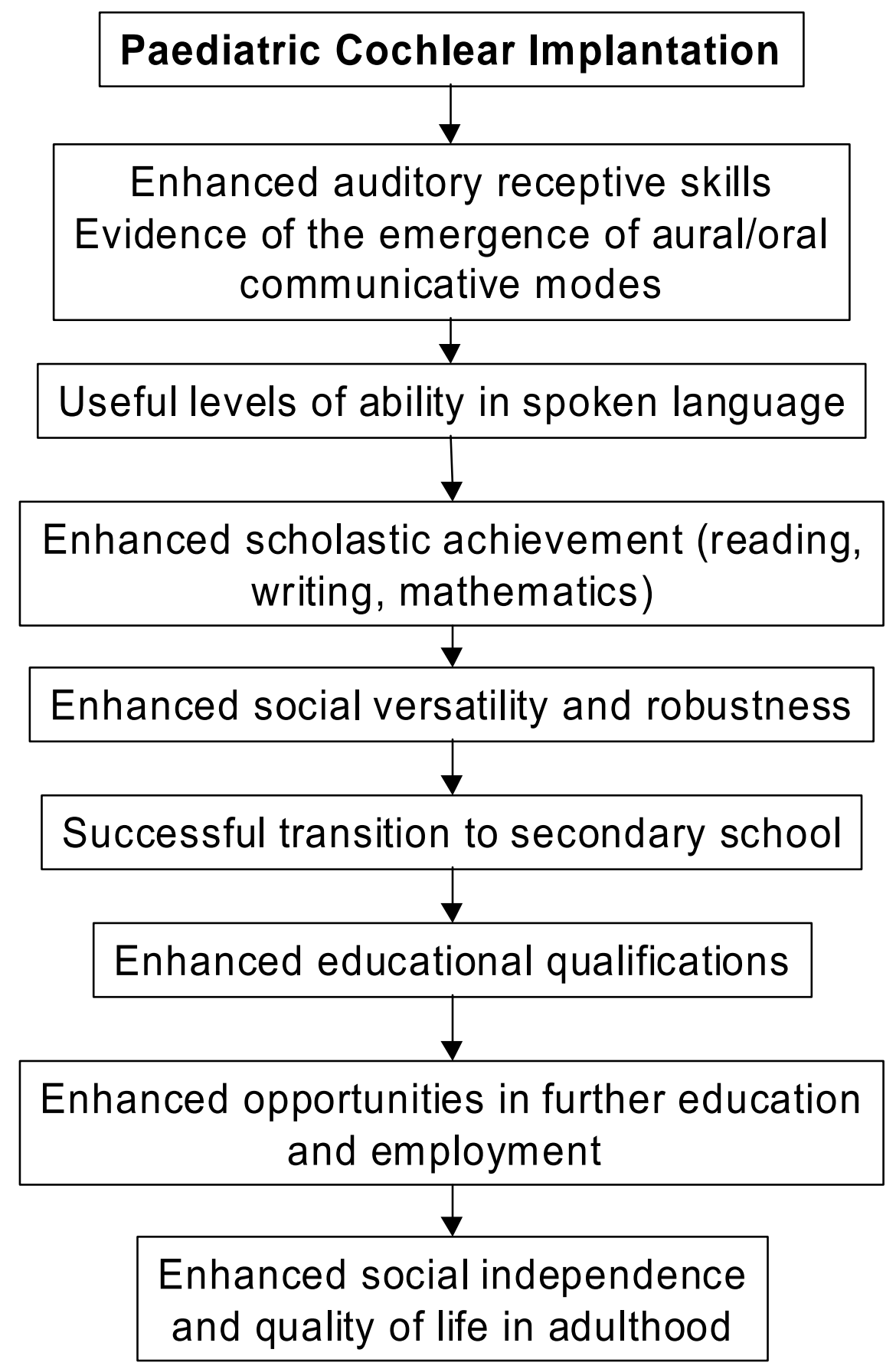




\section{Figure 2}

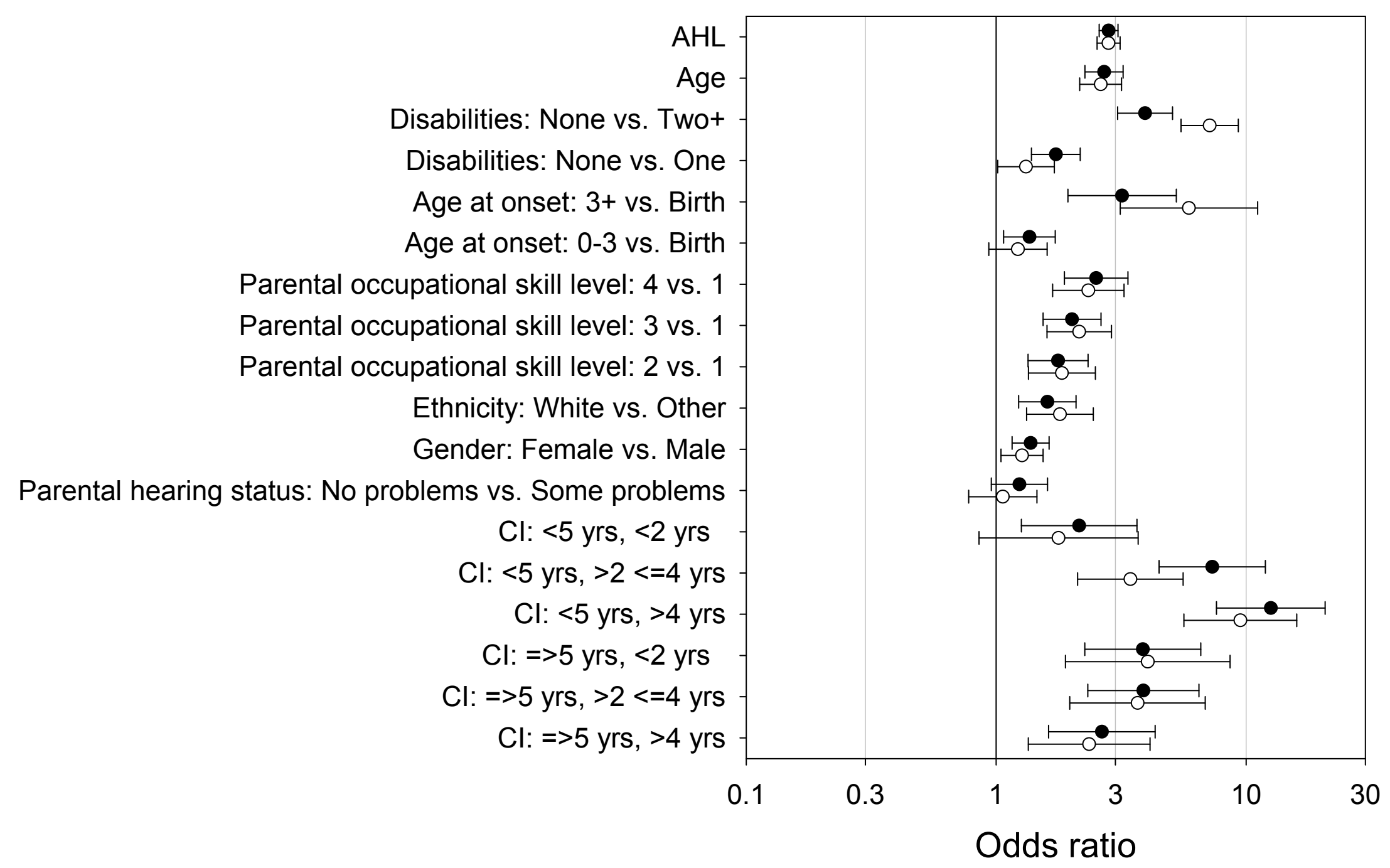




\section{Figure 3}

\section{Duration of use of implants}

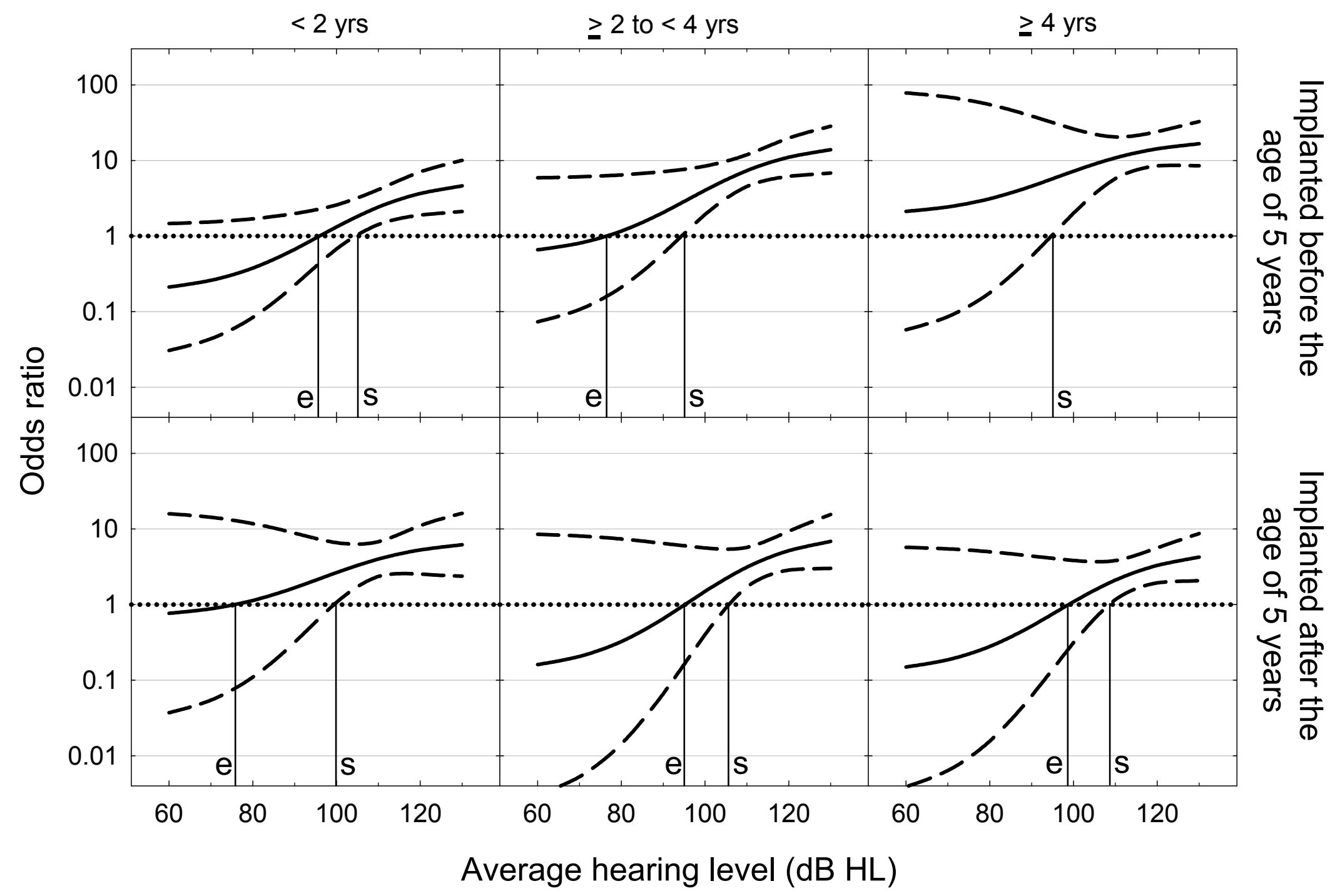


Figure 4

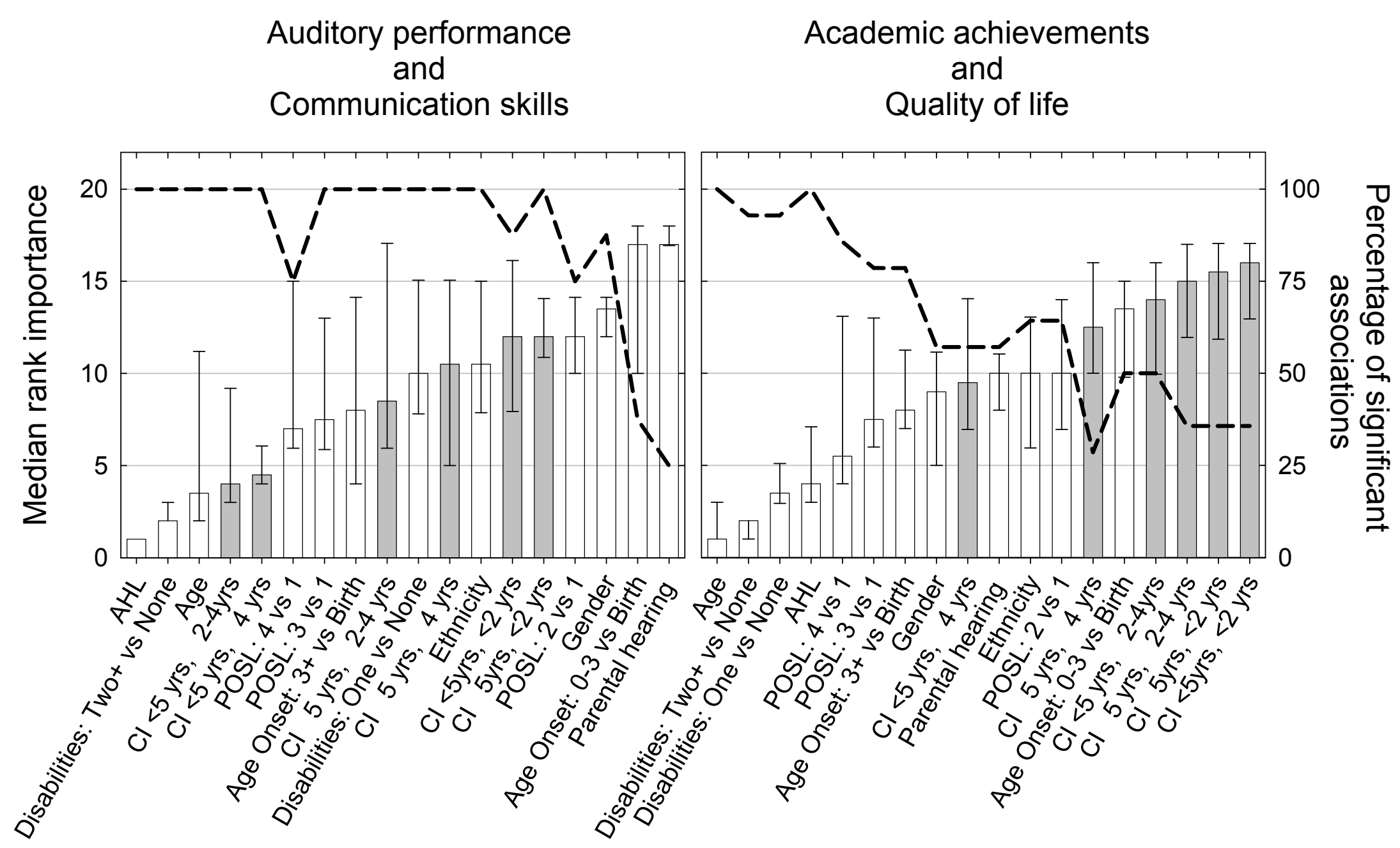


Figure 5

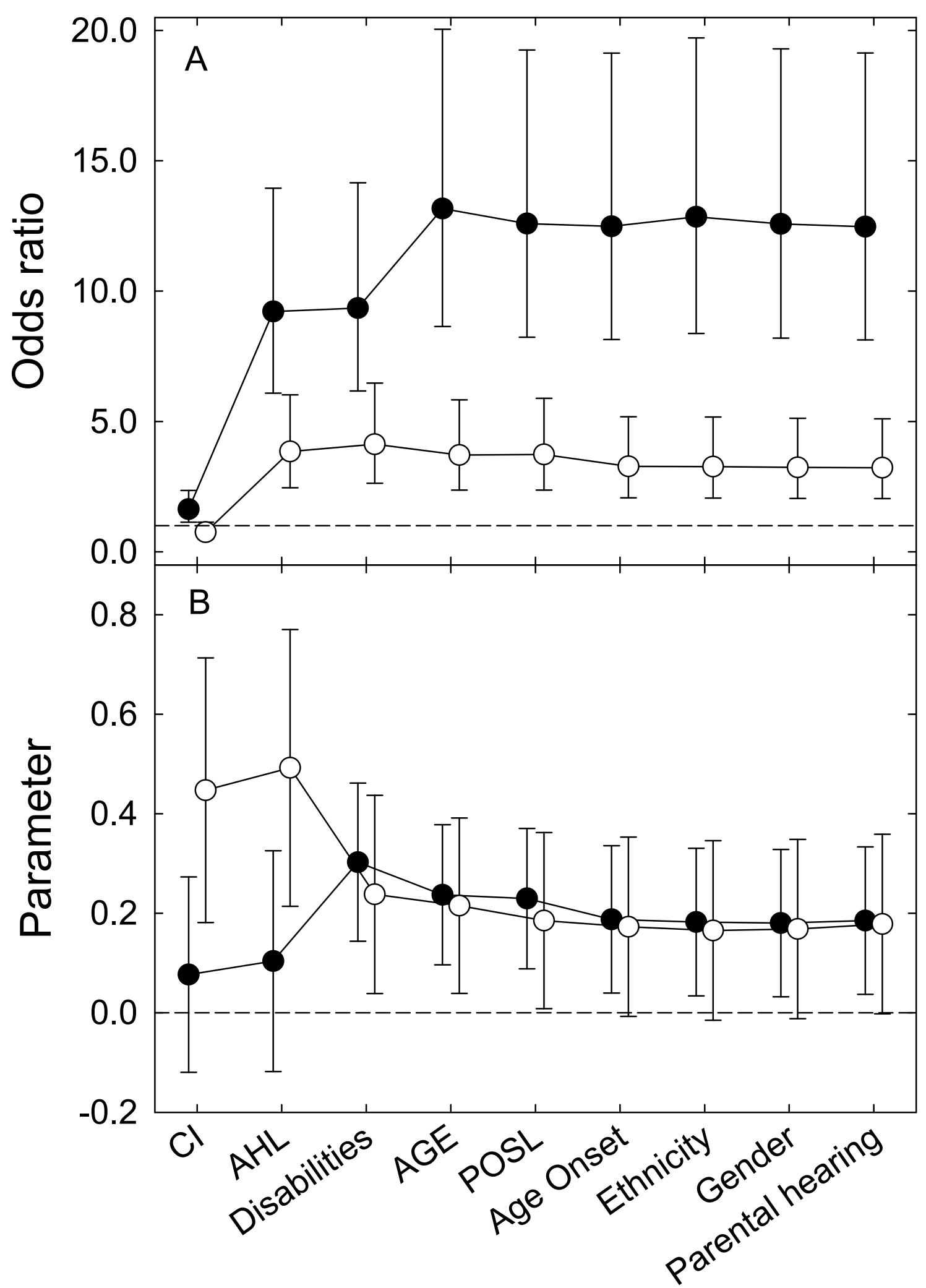


Figure 6

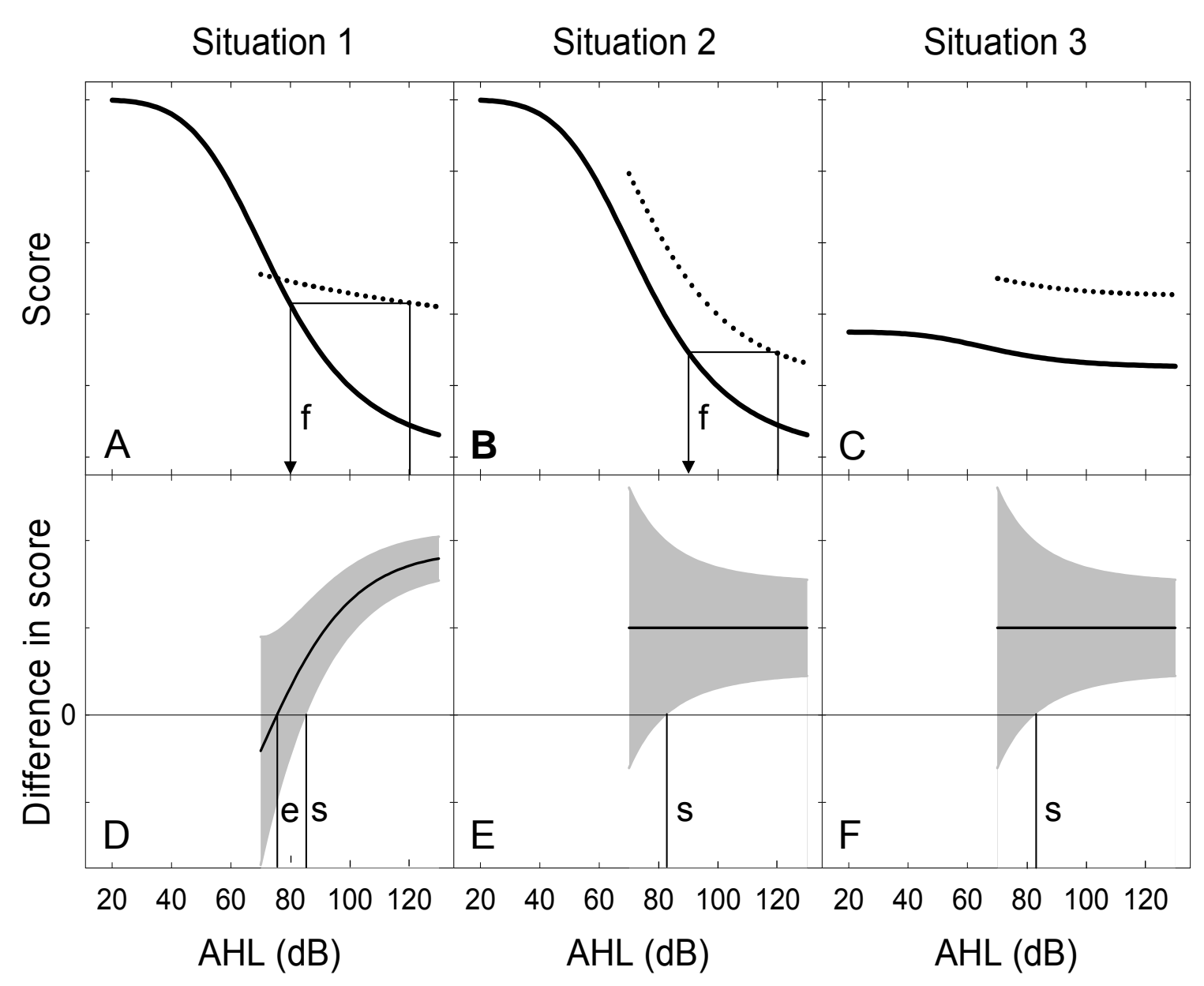

